\title{
Adaptive Resetting of Tuberoinfundibular Dopamine (TIDA) Network Activity during Lactation in Mice
}

\author{
${ }^{\circledR C}$ Carolina Thörn Pérez, ${ }^{1}{ }^{\oplus}$ Jimena Ferraris, ${ }^{1,2}{ }^{\circledR}$ Josina Anna van Lunteren, ${ }^{1}{ }^{\circledR}$ Arash Hellysaz, ${ }^{1}$ \\ (D) María Jesús Iglesias, ${ }^{3}$ and ${ }^{(D}$ Christian Broberger ${ }^{1,2}$ \\ ${ }^{1}$ Department of Neuroscience, Karolinska Institutet, Stockholm, 17177, Sweden, ${ }^{2}$ Department of Biochemistry and Biophysics, Stockholm \\ University, Stockholm, 10691, Sweden, and ${ }^{3}$ Department of Proteomics, School of Biotechnology, Science for Life Laboratory, KTH Royal Institute \\ of Technology, Stockholm, 17177, Sweden
}

Giving birth triggers a wide repertoire of physiological and behavioral changes in the mother to enable her to feed and care for her offspring. These changes require coordination and are often orchestrated from the CNS, through as of yet poorly understood mechanisms. A neuronal population with a central role in puerperal changes is the tuberoinfundibular dopamine (TIDA) neurons that control release of the pituitary hormone, prolactin, which triggers key maternal adaptations, including lactation and maternal care. Here, we used $\mathrm{Ca}^{2+}$ imaging on mice from both sexes and whole-cell recordings on female mouse TIDA neurons in vitro to examine whether they adapt their cellular and network activity according to reproductive state. In the high-prolactin state of lactation, TIDA neurons shift to faster membrane potential oscillations, a reconfiguration that reverses upon weaning. During the estrous cycle, however, which includes a brief, but pronounced, prolactin peak, oscillation frequency remains stable. An increase in the hyperpolarization-activated mixed cation current, $\mathrm{I}_{\mathrm{h}}$, possibly through unmasking as dopamine release drops during nursing, may partially explain the reconfiguration of TIDA rhythms. These findings identify a reversible plasticity in hypothalamic network activity that can serve to adapt the dam for motherhood.

Key words: calcium imaging; dopamine; lactation; network activity

Significance Statement

Motherhood requires profound behavioral and physiological adaptations to enable caring for offspring, but the underlying CNS changes are poorly understood. Here, we show that, during lactation, neuroendocrine dopamine neurons, the "TIDA" cells that control prolactin secretion, reorganize their trademark oscillations to discharge in faster frequencies. Unlike previous studies, which typically have focused on structural and transcriptional changes during pregnancy and lactation, we demonstrate a functional switch in activity and one that, distinct from previously described puerperal modifications, reverses fully on weaning. We further provide evidence that a specific conductance $\left(I_{h}\right)$ contributes to the altered network rhythm. These findings identify a new facet of maternal brain plasticity at the level of membrane properties and consequent ensemble activity.

Received June 20, 2018; revised Feb. 26, 2020; accepted Feb. 27, 2020.

Author contributions: C.T.P. and C.B. designed research; C.T.P., J.F., A.H., and M.J.I. performed research; C.T.P., J.F., and J.A.v.L. analyzed data; C.T.P. and C.B. wrote the paper.

This work was supported by European Research Council ENDOSWITCH 261286, Swedish Research Council Vetenskapsrådet, Swedish Brain Foundation (Hjärnfonden), Strategic Research Program for Diabetes Research at Karolinska Institutet, StratNeuro and Novo Nordisk Fonden to C.B., and Vetenskapsrådet and Hjärnfonden to C.T.P. J.F. was supported by a Wenner-Gren Foundations Fellowship. We thank the CLICK facility for access to confocal microscopy equipment; the plasma profiling facility, headed by Drive Jochen Schwenk, at Science for Life Laboratory (Stockholm) for the immunoassay tools; Elin Dahlberg for expert technical assistance; Drs. Nils-Göran Larsson and Ole Kiehn for generously sharing mouse lines; and members of the C.B. laboratory and Dr. Abdel El Manira for helpful discussions.

The authors declare no competing financial interests.

C. Thörn Pérez' present address: Department of Neurobiology, University of California at Los Angeles, 650 Charles E. Young Drive South, CHS 73-152, Los Angeles, CA 90095.

Correspondence should be addressed to Carolina Thörn Pérez at cthornperez@ucla.edu; or Christian Broberger at christian.broberger@dbb.su.se.

https://doi.org/10.1523/JNEUROSCI.1553-18.2020

Copyright $\odot 2020$ the authors

\section{Introduction}

The mother who has just given birth undergoes a series of physiological changes. Parallel to recalibration after the extensive puerperal organ modifications, physiological and behavioral adaptive modifications enable caring for the offspring (Brunton and Russell, 2008). These changes are orchestrated by an altered blood profile of hormones, which, in turn, likely require reconfiguration at the master level of the endocrine system, the hypothalamus-pituitary axes. Abundant evidence supports that the transcriptional repertoire of neuroendocrine populations undergoes dramatic revision during the bearing and rearing of children (Grattan et al., 2008; Augustine et al., 2018). Far less is, however, known about if, and how, network properties of the hypothalamic neurons that control the pituitary are subject to adaptive resetting during nursing. 
Among the hormones that trigger and sustain the maternal state, prolactin plays a central role (Freeman et al., 2000). Originally named for its ability to trigger crop milk production in pigeons (Stricker and Grüter, 1928; Riddle et al., 1933), prolactin is now understood to induce several of the postpartum physiological changes in the mother (Grattan et al., 2008). These include modifications of ovulatory function (Cohen-Becker et al., 1986; Fox et al., 1987), libido (Dudley et al., 1982), maternal behavior (Bridges et al., 1985; Brown et al., 2017), immune system (Dorshkind and Horseman, 2000), and metabolism and feeding (Sauve and Woodside 1996).

Blood prolactin levels exhibit a marked dynamic profile, driven primarily by reproductive state (Ronnekleiv and Kelly, 1988). While lactation corresponds to a sustained hyperprolactinemic state, beginning during late pregnancy in rodents (Sairenji et al., 2017), circulating prolactin is low under baseline conditions in females and, even more, in males (Guillou et al., 2015; Kalyani et al., 2016). A brief, albeit pronounced, peak appears within the estrous cycle in the transition from proestrus to estrus (Butcher et al., 1974), enabling the maintenance of the corpus luteum and successful implantation (Morishige and Rothchild, 1974).

The dominant control of pituitary prolactin secretion is exerted by neuroendocrine tuberoinfundibular dopamine (TIDA) neurons located in the dorsomedial hypothalamic arcuate nucleus (dmArc; Lyons and Broberger, 2014). These neurons powerfully inhibit prolactin exocytosis by releasing dopamine via the portal capillary vessels to act on dopamine D2 receptors (D2Rs) on the lactotroph cells. Dopamine release usually mirrors circulating prolactin to mediate feedback inhibition (Lerant and Freeman, 1998; Brown et al., 2016), but during lactation, this control is proposed to be overridden through, for example, downregulated dopamine biosynthesis (Wang et al., 1993), enabling prolactin to remain elevated for long periods to enable nursing (Grattan, 2015; Le Tissier et al., 2015; Yip et al., 2019).

Yet, neurons calibrate their action not merely by the number of receptors expressed and transmitter produced, but equally important by the cellular and network activity patterns. The issue of adaptive control of TIDA neurons is interesting, not only for their role in reproduction and nursing, but also for the intriguing pattern of their discharge activity, organized as slow, regular membrane potential oscillations (Lyons et al., 2010). These oscillations can be observed by whole-cell patchclamp recording as well as $\mathrm{Ca}^{2+}$ imaging in both rats and mice, albeit with species-specific features in network configuration (Stagkourakis et al., 2018). TIDA network activity can be modulated by several hormones and transmitters implicated in prolactin control (Briffaud et al., 2015; Zhang and van den Pol, 2015; Lyons et al., 2016; Stagkourakis et al., 2016). In the pituitary, the ensemble activity of lactotrophs has been shown to be reorganized as a female enters nursing, with remarkably long-lasting effects (Hodson et al., 2012). If and how the network activity of TIDA neurons, the master control of the lactotropic axis, are reconfigured as a consequence of reproductive state remains, however, largely unknown. Here, we used $\mathrm{Ca}^{2+}$ imaging and whole-cell recordings, combined with in situ hybridzation (ISH), in mice to determine the cellular and network activity of these neurons during different reproductive states. We demonstrate a reversible shift in ensemble activity during lactation, and identify a candidate underlying mechanism in altered membrane properties.

\section{Materials and Methods}

Experimental design

Experiments were approved by the local animal research ethical committee, Stockholms Norra Djurförsöksetiska Nämnd.

Experiments were performed in F1 adult (4-6 months) female and male transgenic mice (on a C57BL/6J background) expressing GCaMP3 or tdTomato under the control of the dopamine transporter (DAT) promoter (Ekstrand et al., 2007). Females were divided into different groups according to the estrogen cycle: proestrus, estrus, diestrus/metestrus (determined by the cytology of the vaginal smears) (McLean et al., 2012). For the lactating studies, dams were used between days 7 and 10 of lactation. For weaning studies, pups were removed from the dams at postnatal day 21, which were used for recordings 3 weeks later.

Animals were anesthetized with pentobarbital, decapitated, and the brain was dissected and sliced at $4^{\circ} \mathrm{C}$ in slicing solution of the following composition (in mM): sucrose (213), $\mathrm{KCl}(2), \mathrm{NaH}_{2} \mathrm{PO}_{4}$ (1.3), $\mathrm{NaHCO}_{3}$ (26), $\mathrm{CaCl}_{2}$ (2), $\mathrm{MgCl}_{2}$ (2), and glucose (10); 250- $\mu$ m-thick coronal hypothalamic slices were cut on a vibratome. Slices where continuously perfused with oxygenated aCSF containing the following (in $\mathrm{mM}$ ): $\mathrm{NaCl}$ (127), $\mathrm{KCl}$ (2), $\mathrm{NaH}_{2} \mathrm{PO}_{4}$ (1.3), $\mathrm{NaHCO}_{3}$ (26), $\mathrm{CaCl}_{2}$, (2.4), $\mathrm{MgCl}_{2}$ (1.3), and glucose (10). Three to five slices per animal, with a minimum of four oscillating cells per slice, were used for the network-mapping experiments.

\section{Immunofluorescence}

Adult male mice $(n=4)$ were anesthetized and perfused via the ascending aorta with a fixative containing $4 \% \mathrm{PFA}$ and $0.2 \%$ picric acid. Brains were dissected, cryo-protected in sucrose, rapidly frozen with $\mathrm{CO}_{2}$ gas, and sectioned on a cryostat at $14 \mu \mathrm{m}$ thickness. Tissue sections spanning the entire rostrocaudal length of the Arc were processed for immunofluorescence (Foo et al., 2014), using primary anti-TH antiserum (1:2000; raised in rabbit; AB152; Millipore, RRID:SCR_008983) combined with anti-GFP antiserum (1:4000; raised in chicken; GFP-1020; Aves Labs, catalog \#GFP-1020, RRID:AB_10000240). TH was visualized with Alexa-594-conjugated secondary antisera (1:500; raised in donkey; A21207; Thermo Fisher Scientific), and GFP was visualized with tyramide signal amplification Plus (PerkinElmer) using HRP-conjugated secondary antisera (1:500; raised in goat; 103-035-155; Jackson ImmunoResearch Laboratories) and fluorescein tyramide substrate. Tissue sections were mounted with 2.5\% 1,4-diazabicyclo[2.2.2]octane in $100 \%$ glycerol. Fluorescence micrograph montages were automatically generated by taking consecutive pictures with a Carl Zeiss Axio Imager M1 and merging them using MBF Neurolucida computer software. Confocal micrographs were acquired with an Olympus FV1000 microscope and visualized in BitPlane Imaris. For final images, brightness, contrast, and sharpness were adjusted digitally.

\section{RNAScope assay}

Adult mice (nulliparous females in estrus and lactating dams) were deeply anesthetized with isoflurane. The brain was removed and rapidly frozen on dry ice. Brains were stored at $-80^{\circ} \mathrm{C}$ until sectioning. Coronal sections $(14-20 \mu \mathrm{m})$ of the hypothalamus were cut on a cryostat (CryoStar NX70, Thermo Fisher Scientific) and mounted on SuperFrost Plus slides (Thermo Fisher Scientific). Slides were processed for FISH of multiple target RNAs simultaneously according to manufacturer protocols for RNAScope (Advanced Cell Diagnostics). Briefly, sections were postfixed in $10 \%$ neutral buffered formalin, washed, and dehydrated in sequential concentrations of ethanol $(50 \%, 70 \%$, and $100 \%)$ at room temperature. Samples were treated with protease, then incubated for $2 \mathrm{~h}$ at $40^{\circ} \mathrm{C}$ in the presence of target probes to allow for hybridization. A series of three amplification steps is necessary to provide substrate for target fluorophore labeling. After labeling, samples were counterstained by incubating for $30 \mathrm{~s}$ at room temperature with DAPI (Advanced Cell Diagnostics). Prolong Gold Antifade Mountant (Invitrogen) was applied to each slide before coverslipping. Images were acquired by confocal laser scanning microscope (LSM710 META, Carl Zeiss). High-resolution $z$-stack confocal images were taken at $0.3 \mu \mathrm{m}$ intervals. Cell-by-cell expression profiles in the ROI (DAT mRNA-positive neurons in the $\mathrm{dm} A r c)$ were achieved by semiquantitative analysis where the number of 
dots (i.e., single RNA transcripts) in each bin was estimated as described by the manufacturer (Advanced Cell Diagnostics score: 0, no staining; 1 , 1-3 dots/cell profile; 2, 4-9 dots/cell profile; 3, 10-14 dots/cell profile; and $4, \geq 15$ dots/cell profile) and the overall score (range 0-400) was calculated as follows:

$\mathrm{H}$-score $=\sum(\mathrm{ACD}$ score $*$ percentage of cells per bin $)$

\section{Prolactin level analysis}

Mice were anesthetized with an intraperitoneal dose of pentobarbital, and trunk blood samples were collected after decapitation. The serum was obtained by leaving the blood to clot at room temperature for $30 \mathrm{~min}$ and centrifugation at $4^{\circ} \mathrm{C}$ for $15 \mathrm{~min}(10,000 \mathrm{rpm})$. The supernatant was aliquoted and stored at $-80^{\circ} \mathrm{C}$. Prolactin serum levels were measured by bead-based sandwich immunoassay (Qundos et al., 2014). Affinity reagents and the mouse recombinant prolactin protein, purchased from RnD Biosystems Douset kit (RnD DY1445), were used to quantify prolactin levels in serum. In brief, a goat anti-mouse prolactin capture antibody, as well as goat $\operatorname{IgG}$, were covalently coupled to color-coded magnetic beads (MagPlex microspheres), which, together with plain beads (as negative control), composed the bead-based array. The coupling efficiency for the antibody was determined via R-phycoerythrin-labeled anti-goat IgG antibody (Jackson ImmunoResearch Laboratories).

Serum samples were diluted 1:5 in assay buffer, and then $45 \mu \mathrm{l}$ was combined with $5 \mu \mathrm{l}$ of the bead array in microliter plates (Greiner). Samples were incubated for $2 \mathrm{~h}$ on a shaker at room temperature and $650 \mathrm{rpm}$. Beads were washed on a magnet with PBS-T using a plate washer (EL406, BioTek), followed by $1 \mathrm{~h}$ incubation of $70 \mathrm{ng} / \mathrm{ml}$ biotinylated detection antibody (part B-DY1445). Beads were washed again, and $0.5 \mu \mathrm{g} / \mathrm{ml}$ R-phycoerythrin-labeled streptavidin (Invitrogen) in PBS$\mathrm{T}$ was added and incubated for $30 \mathrm{~min}$. Finally, washed samples were measured in PBS-T using the MAGPIX instrument (Luminex). Median fluorescence intensity and a standard curve were obtained for all samples. A 5PL parameter logistic curve was generated to interpolate median fluorescence intensity into protein concentration $(\mathrm{ng} / \mathrm{ml})$.

\section{Calcium imaging}

The activity of oscillating neurons was recorded in a chamber that was continuously perfused with oxygenated aCSF and maintained at $\sim 36^{\circ} \mathrm{C}$ on a microscope system (Carl Zeiss). Fluorescence images were captured with a CCD camera (Evolve, Photometrics) monitored by fluorescence changes under imaging acquisition in ImageJ (National Institutes of Health) or Metafluor software. Imaging frames of $512 \times 512$ pixels were acquired at $4 \mathrm{~Hz}$, during $90 \mathrm{~s}$ using a $20 \times$ water-immersion objective (Carl Zeiss), and image sequences were analyzed with custom software written in ImageJ (National Center for Microscopy and Imaging Research: ImageJ Mosaic Plug-ins, RRID:SCR_001935) and MATLAB (The MathWorks, RRID:SCR_001622).

Individual cells were marked as ROIs from the image sequences (i.e., all positive cells in one plane). Consistent with previous studies in mice, both oscillating and nonoscillating DAT-GCaMP3 cells were found (Zhang and van den Pol, 2015; Stagkourakis et al., 2018). Our focus in this study was on the oscillating population, which was selected by the fold difference in the intensity signal $(\geq 1 \%)$ and the rhythmicity index (RI; defined below; $\geq 0.2$ ).

The recorded intensity signals were presented as relative changes of fluorescence in each of the selected ROIs and expressed as $(\Delta \mathrm{F} / \mathrm{F} 0)$, where $\mathrm{F} 0$ is the minimum fluorescence value of the ROI and $\Delta F=(\mathrm{F}-$ F0 $\times 100$. The frequency was determined using a power spectrum. The signal was high pass filtered using a cutoff at $0.1 \mathrm{~Hz}$, and the RI was defined as RI $=\beta \alpha$, where $\alpha$ is the amplitude of the peak at zero lag and $\beta$ is the amplitude of the peak at the period of the $\mathrm{Ca}^{2+}$ oscillations, usually the second peak in the auto-correlogram (see Fig. $3 \mathrm{Ba}$ ) (Levine et al., 2002). Thus, the closer $\mathrm{RI}$ is to 1 , the more rhythmic is the $\mathrm{Ca}^{2+}$ signal. A MATLAB script described by Smedler et al. (2014) was used to illustrate and determine the correlation matrix value and correlated cell pairs were defined as the ones with autocorrelation coefficient $\geq 0.8$.

Simultaneous $\mathrm{Ca}^{2+}$ imaging and whole-cell patch-clamp recording (see below) were performed using a $64 \times$ water-immersion objective. Whole-cell recordings were obtained through visualizing DAT-GCaMP3 cells and then adapting them to the differential contrast images. For temporal synchronization of acquired images and recorded membrane potential oscillations, camera exposure data indicating the occurrence of each frame were obtained from the imaging system and recorded simultaneously with the intracellular signal using pClamp software (Molecular Devices).

\section{Electrophysiology}

For the whole-cell recording experiments, identical conditions of perfusion rate and temperature were kept as with $\mathrm{Ca}^{2+}$ imaging. TIDA neurons, visualized as DAT-GCaMP3 or DAT-tdTomato, were recorded using patch electrodes pulled from borosilicate glass microcapillaries. Whole-cell recordings were performed in current- or voltage-clamp mode using a Multiclamp 700B amplifier (Molecular Devices). Bridge balance and pipette capacitance compensation were automatically adjusted. Liquid junction potential was $15.2 \mathrm{mV}$ and not compensated. Patch pipettes had resistances of 4-7 M $\Omega$ and contained the following (in $\mathrm{mM}$ ): K-gluconate (140), $\mathrm{KCl}(10), \mathrm{KOH}$ (1), $\mathrm{Na}_{2} \mathrm{ATP}$ (2), and HEPES (10). The $\mathrm{pH}$ was adjusted to 7.4 with $1 \mathrm{M} \mathrm{KOH}$ and the osmolarity to $280 \mathrm{mOsm}$. Solutions of pharmacological agents were bathapplied at a perfusion rate of $1 \mathrm{ml} / \mathrm{min}$.

Consecutive hyperpolarizing voltage steps $(1 \mathrm{~s},-140 \mathrm{mV}$ to $-70 \mathrm{mV})$ were performed under $\mathrm{Na}^{+}$channel blockade by TTX $(500$ nM; Sigma Millipore) in the presence or absence of ZD7288 (Tocris Bioscience). Drugs were kept as concentrated stocks dissolved in water and kept frozen at $-20^{\circ} \mathrm{C}$. During the experiments, the drugs were diluted to the final concentration in aCSF and bath-applied through the perfusion system.

The signal was amplified, and low pass filtered online at $10 \mathrm{kHz}$, and digitized. Data were acquired with Clampex software and analyzed using Clampfit (pCLAMP 10, Molecular Devices), Spike2 4.16 (Cambridge Electronic Design) or WinEDR, Electrophysiological data recorder 3.8.7 (University of Strathclyde) software.

\section{Statistical analysis}

Statistical analyses were performed using GraphPad (Prism) software. Assumptions of normality and homogeneity of variance were tested before conducting the following statistical approaches (KolmogorovSmirnov test). Student's $t$ test and Mann-Whitney were used to measure the significance of the differences between two unpaired samples. Multiple groups were compared using ANOVA with Tukey's or Sidak's test as a post hoc comparison. In case the results failed the test of normality, Kruskal-Wallis ANOVA was performed $(\alpha=0.05)$ with Dunn's multiple comparison. Unless otherwise stated, data are expressed as mean \pm SEM, and $n$ indicates the number of animals, network maps, or cells as specified. Box plots represent the interquartile (25\%-75\%) ranges; me$\mathrm{dian} /$ mean values with whiskers indicate maximum and minimum values. Statistical significance was set at $p<0.05$.

\section{Results}

\section{GCaMP3 dynamics}

To access TIDA cells in acute hypothalamic slices, we used a transgenic mouse line expressing the genetically encoded $\mathrm{Ca}^{2+}$ indicator, GCaMP3 (under the control of the DAT promoter), which is expressed in dmArc dopamine neurons (i.e., the TIDA population) (Lorang et al., 1994). GCaMP3 expression was verified by GFP-like immunoreactivity and colocalization of the rate-limiting enzyme in dopamine biosynthesis, TH (Fig. 1A,B).

Voltage-gated $\mathrm{Ca}^{2+}$ channels mediate a critical step in stimulus-secretion coupling, converting action potential-triggered depolarization to vesicular release of neurotransmitters (Katz and Miledi, 1970). To determine the relationship between 


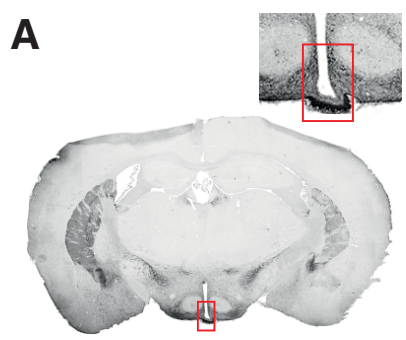

Bregma $-1.58 \mathrm{~mm}$
$\mathrm{Ba}$

TH-IR

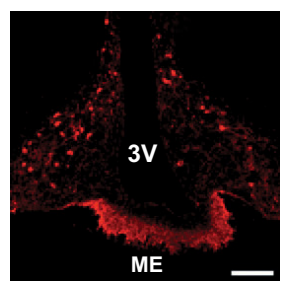

$\mathrm{Bb}$

GFP

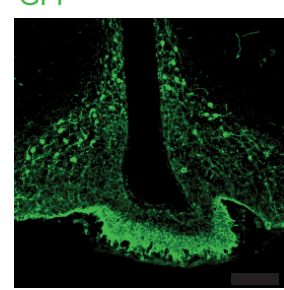

Bc

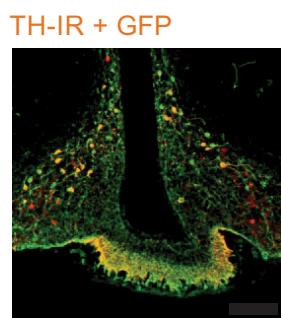

C

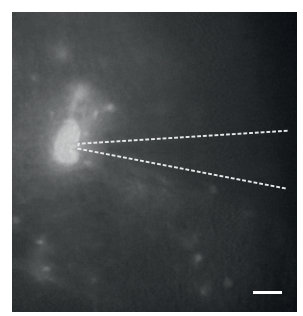

\section{$\mathrm{Da}$}

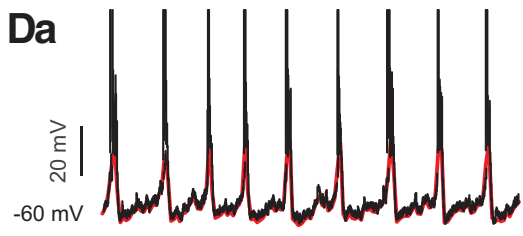

$\mathrm{Db}$

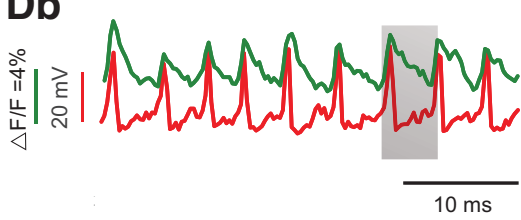

Dc

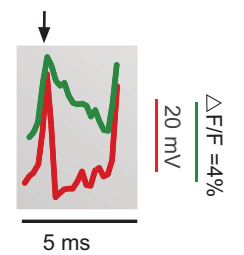

E

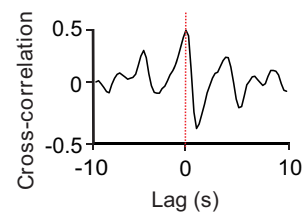

Figure 1. GCaMP3 $\mathrm{Ca}^{2+}$ imaging faithfully correlates to electrophysiologically recorded membrane potential oscillations in TIDA neurons. $A$, Fluorescence micrograph in the coronal plane of a male DAT-GCaMP3 mouse brain at the level of the arcuate nucleus. Converted to grayscale and inverted for better contrast. Inset, Higher magnification of marked region. Ba-c, Confocal micrographs of marked region in $\boldsymbol{A}$, immunostained for Tyrosine Hydroxylase (TH) (red; $\boldsymbol{B} \boldsymbol{a}$ ), GFP (green; $\boldsymbol{B} \boldsymbol{b}$ ), and merged (Bc). Yellow represents colocalization of signals. $C$, Photomicrograph of a fluorescent DAT-GCaMP3 neuron in the dmArc during whole-cell patch-clamp recording. Dashed line outlines recording pipette. Da, Whole-cell current-clamp recording from a DAT-GCaMP3 neuron. Downsampled trace overlaid in red. $\boldsymbol{D} \boldsymbol{b}$, Downsampled trace from $\boldsymbol{D} \boldsymbol{a}$ aligned with the simultaneously recorded $\mathrm{Ca}^{2+}$ imaging activity (green). Note coincident activity peaks in both signals. $\boldsymbol{D} \boldsymbol{c}$, Gray box in $\boldsymbol{D} \boldsymbol{b}$ expanded to illustrate high peak-to-peak correlation (black arrow) and the slow decay kinetics of the $\mathrm{Ca}^{2+}$ signal compared with the membrane depolarization. $\boldsymbol{E}$, Cross-correlogram between the downsampled membrane potential and the $\mathrm{Ca}^{2+}$ activity of trace (Dd). Scale bars: (in $\left.\boldsymbol{B a}\right) \mathbf{B a}-\boldsymbol{c}, 100 \mu \mathrm{m} ; \boldsymbol{C}, 25 \mu \mathrm{m}$. 3V, Third ventricle; $\mathrm{ME}$, median eminence.

GCaMP3-visualized $\mathrm{Ca}^{2+}$ fluctuations and membrane potential oscillations in TIDA neurons, we performed simultaneous $\mathrm{Ca}^{2+}$ imaging and whole-cell recordings in DAT-GCaMP3 neurons (Fig. 1C), revealing a strong correlation with GCaMP3 waveform peaks sharply phase-locked to the TIDA UP states (Fig. 1D; $n=13$ of 13 cells). The characteristic fast rise and slow decay of the $\mathrm{Ca}^{2+}$ signal are illustrated in Figure $1 D b, c$. Cross-correlation analysis of the two signals (Fig. $1 E$ ) highlights the positive correlation $(<0.5, n=13$ of 13$)$ between signal peaks, and the negative correlation between $\mathrm{Ca}^{2+}$ signal decay and the slow depolarization phase of the TIDA oscillation. Thus, $\mathrm{Ca}^{2+}$ imaging can be used as a reliable readout of the TIDA oscillation in individual neurons as first identified by electrophysiology (Lyons et al., 2010).

\section{TIDA oscillation frequency increases during lactation}

To determine whether different activity states in the lactotropic axis are paralleled by changes in TIDA network behavior, $\mathrm{Ca}^{2+}$ imaging was performed on dmArc slices from DAT-GCaMP3 mice where circulating prolactin is low (juvenile males and females during diestrus/metestrus), transiently elevated (proestrus, estrus), or sustained elevated (lactation). Estrous cycle stages were determined by vaginal smears. The cytology of diestrus and metestrus smears could not consistently be reliably differentiated from each other; but as they are distinct from the other states by the presence of leukocytes, these two states were pooled into one group $(\mathrm{D} / \mathrm{M})$. While the characteristic cytological profiles of proestrus and estrus are distinct, there was no significant difference in the oscillation frequency between these states (Fig. $2 B ; t_{(244)}=1.48, p=0.14$, unpaired $t$ test), so data from these two groups were also pooled $(\mathrm{P}+\mathrm{E})$. In all physiological conditions, the proportion of oscillating cells remained similar (D/M: $53.2 \pm 8.6 \%$; $\mathrm{P}+\mathrm{E}$ : $43.7 \pm 5.1 \%$; lactating $46.9 \pm 9.5 \%$; of all fluorescent cells, and no significant differences between groups; cumulative total average for all groups: $47.9 \pm 10.0 \%$ ). Figure $2 \mathrm{Aa}-d$ shows traces of simultaneous $\mathrm{Ca}^{2+}$ fluctuations from five cells from a single slice in the experimental groups. The series of images from all groups (males, D/M, estrus, and lactating) revealed a large distribution and overlapping dispersal of oscillation frequencies.

Oscillation frequency was not significantly different in comparisons between adult males $(0.25 \pm 0.06 \mathrm{~Hz})$ and the estrous cycle groups $\left(\mathrm{D} / \mathrm{M}=0.32 \pm 0.06 \mathrm{~Hz}, p_{\mathrm{adj}}=0.73 ; \mathrm{P}+\mathrm{E}=0.36 \pm\right.$ $0.06 \mathrm{~Hz}, p_{\text {adj }}=0.25 ; p$ values for Tukey's multiple comparison test, which followed one-way ANOVA to reflect difference across groups, $\left.F_{(3,33)}=9.89, p<0.001\right)$. During lactation, TIDA neuron oscillation activity persisted, consistent with a previous report (Romanò et al., 2013). The mean frequency of the $\mathrm{Ca}^{2+}$ signal fluctuation was, however, significantly faster compared with the other groups $(0.53 \pm 0.04 \mathrm{~Hz}$; Fig. $2 C)$. We found no correlation between the number of oscillating cells in a slice and the mean oscillating frequencies within the nulliparous female population (Fig. $2 D ; R^{2}<0.05$ ), suggesting that oscillation period does not depend on active population size.

As summarized above, serum prolactin levels are shaped by TIDA neurons, which exert tonic inhibition on pituitary lactotrophs (see Grattan, 2015). We performed a bead-based sandwich immunoassay to directly study serum prolactin levels in the mice used in the recordings. Prolactin levels were significantly different between males and the $\mathrm{P}+\mathrm{E}$ group and between males and the lactating group (Fig. $2 E ; F_{(3,27)}=3.13$, $p=0.04$, one way ANOVA). 
$\mathrm{Aa}$

Male

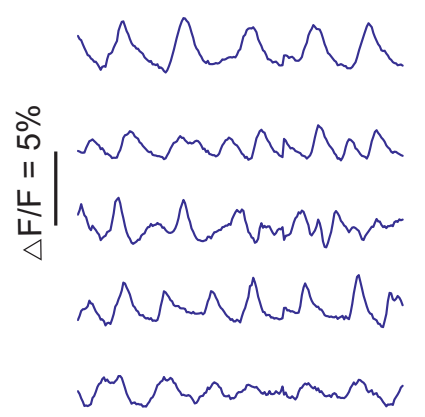

$\mathrm{Ab}$

Diestrus/Metestrus

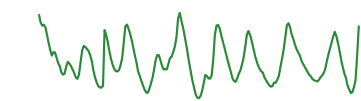

$\therefore$ HWMW

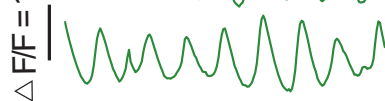

MNan $\wedge$

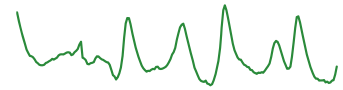

Ac

Estrus

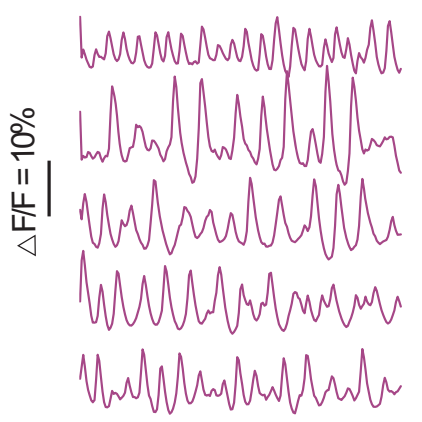

Ad

\section{Lactating}

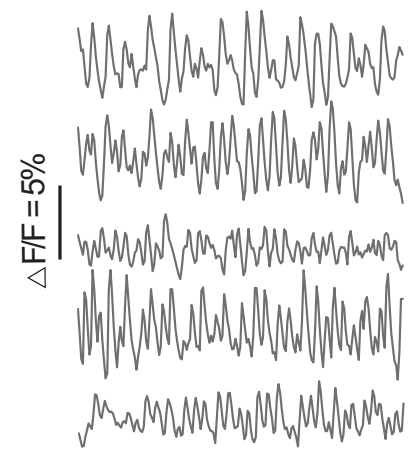

$20 \mathrm{~s}$
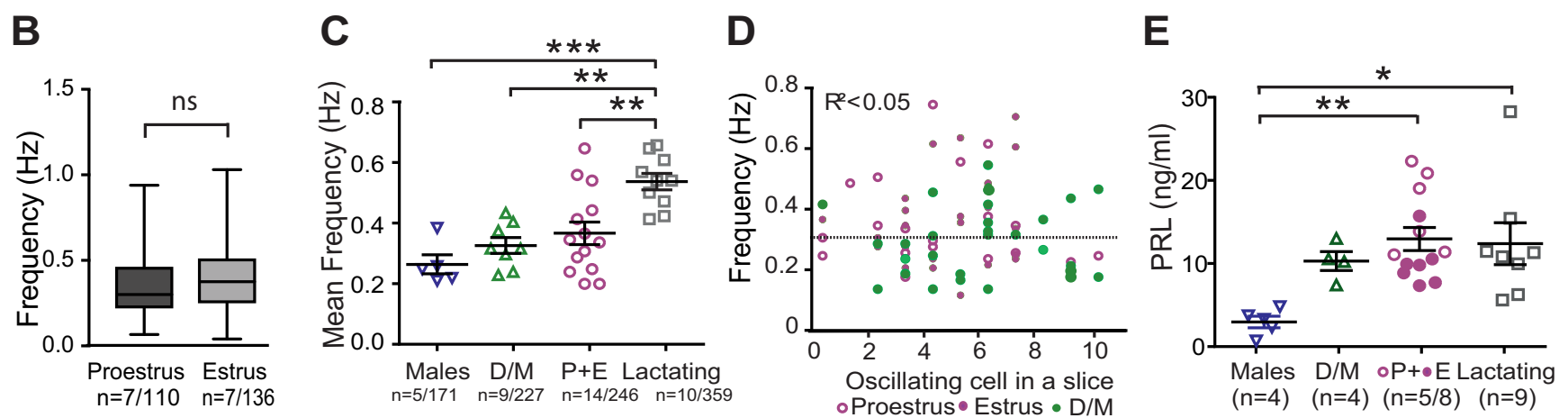

Figure 2. The frequency of TIDA neuron $\mathrm{Ca}^{2+}$ oscillations increases during lactation. $\boldsymbol{A}$, Representative concomitant traces of $\mathrm{Ca}^{2+}$ fluctuations in DAT-GCaMP3 neurons in the dmArc from the same slice in adult males $(\boldsymbol{A} \boldsymbol{a})$, female in diestrus/metestrus $(\mathrm{D} / \mathrm{M} ; \boldsymbol{A} \boldsymbol{b})$, female in estrus (from the proestrus + estrus group; $\mathrm{P}+\mathrm{E} ; \boldsymbol{A c})$, and lactating dam $(\boldsymbol{A d})$. $\boldsymbol{B}$, Box plot represents the frequency of the $\mathrm{Ca}^{2+}$ oscillations in DAT-CGaMP3 neurons in the dmArc recorded from female mice in proestrus and estrus. There is no significant difference between the two groups (unpaired Student's $t$ test, $p=0.14$ ). $n$ indicates the number of animals/neurons. Box plots represent the interquartile ranges (square) and median (line). Values with whiskers indicate minimum and maximum values. C, Scatter plots represent the mean frequency and SEM of oscillating DAT-GCaMP3 neurons in the dmArc (i.e., all oscillating cells, from all slices of a single mouse). The mean frequency was significantly different between the lactating group and the male, $\mathrm{D} / \mathrm{M}$, and $\mathrm{P}+\mathrm{E}$ groups. ${ }^{* * *} p<0.001$ (one-way ANOVA with Tukey's multiple comparison as post hoc test). ${ }^{* *} p>0.01$ (one-way ANOVA with Tukey's multiple comparison as post hoc test). All other comparisons between groups are nonsignificant. $n$ indicates the number of animals/cells. $D$, The number of oscillating cells in a slice plotted against the mean oscillation frequency of the same slice. No correlation (Pearson correlation: $R^{2}<0.05$ ) is found, suggesting that the number of active cells within a preparation does not influence the speed of the activity. $\boldsymbol{E}$, Serum prolactin concentration measured by immunoassay in the experimental groups shown in $\boldsymbol{C}$. ${ }^{*} p>0.05$ (one-way ANOVA with Tukey's multiple comparison as post hoc test). ${ }^{* *} p>0.01$ (one-way ANOVA with Tukey's multiple comparison as post hoc test). All other comparisons between groups are nonsignificant. $n$ indicates the number of samples/animals.

Together, these results suggest that, while prolactin levels vary dynamically both during the estrous cycle and during nursing, it is only in conjunction with long-term changes in prolactin output (i.e., nursing), and not for more transient elevations (i.e., proestrus/estrus), that plastic changes that shift TIDA oscillation frequency appear.

TIDA rhythmicity decreases during lactation

To further investigate the extent of TIDA network rearrangement across high- and low-prolactin states, we conducted a cross-correlation analysis of the $\mathrm{Ca}^{2+}$ fluctuations between all oscillating cells in a single network (see Materials and Methods). Figure $3 A$ shows representative network maps from males, estrous stages, and lactation. The color represents level of cellto-cell correlation according to the $\mathrm{Ca}^{2+}$ activity profiles. While correlated cell pairs could be observed in all stages, they were rare (one or two per slice), suggesting an overall absence of synchronization. Figure $3 C$ summarizes the matrix value of each map in different physiological states. The differences in functional connectivity were not significant between groups $\left(F_{(3.116)}=2.358, p=0.0753\right.$, one-way ANOVA; $n$ indicates the number of network maps), suggesting that direct communication between oscillating cells is low (and that a common organizing input is unlikely, at least within the anatomic confines of the slice preparation), and that this condition remains unchanged across the physiological states that we examined. Thus, the state-dependent changes that we observed in oscillation frequency are unlikely to be a consequence of modified connectivity in the network.

We also determined whether the oscillation rhythmicity is related to the physiological state and/or to the frequency, by analyzing the auto-correlation of each oscillating cell. Representative auto-correlograms are shown in Figure $3 B a-d$. During lactation, the RI (see Materials and Methods) of the cells decreased significantly compared with other states, indicating a less regular oscillation pattern (Fig. $3 D ; \mathrm{H}=123.5$, $p<0.0001$, Kruskal-Wallis). Notably, rhythmicity did not exhibit a correlation to frequency analyzed across individual cells, suggesting that these factors are independent variables (Fig. $3 E ; R^{2}<0.05$ ). 
Aa

Males
Ab

Diestrus/Metestrus

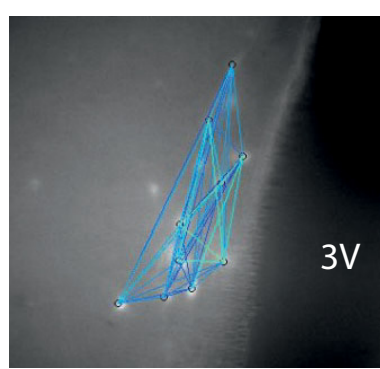

$\mathrm{Bb}$

Diestrus/Metestrus

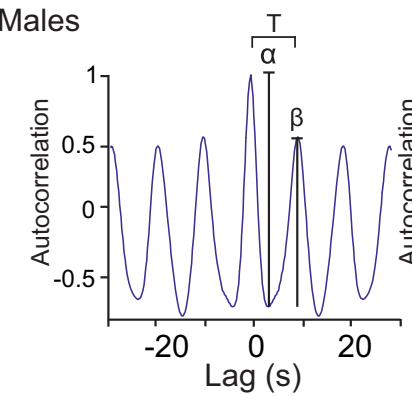

C

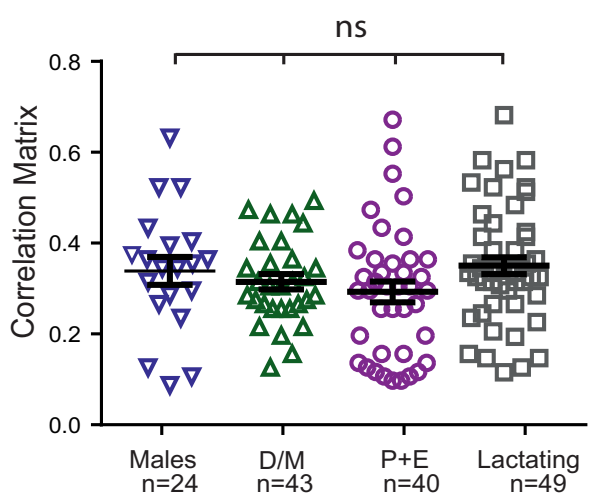

Ac

Estrus

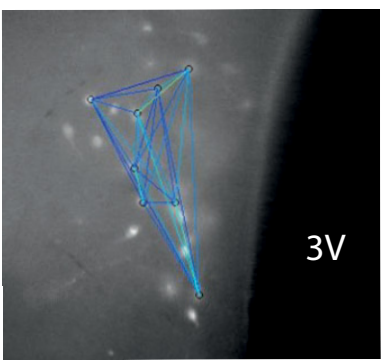

Bc

Estrus

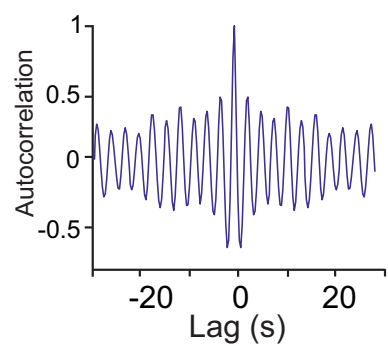

Ad

Lactating

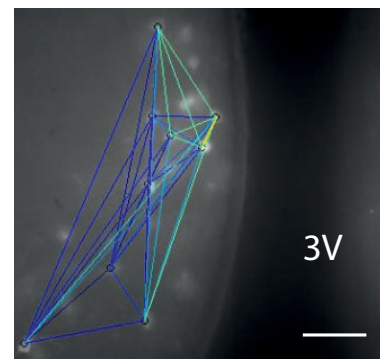

Bd

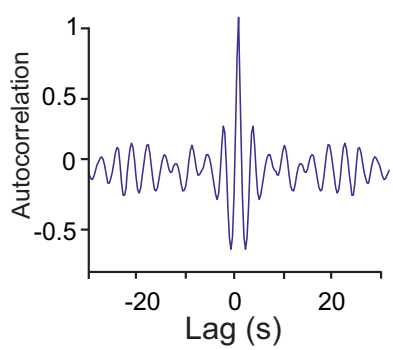

E
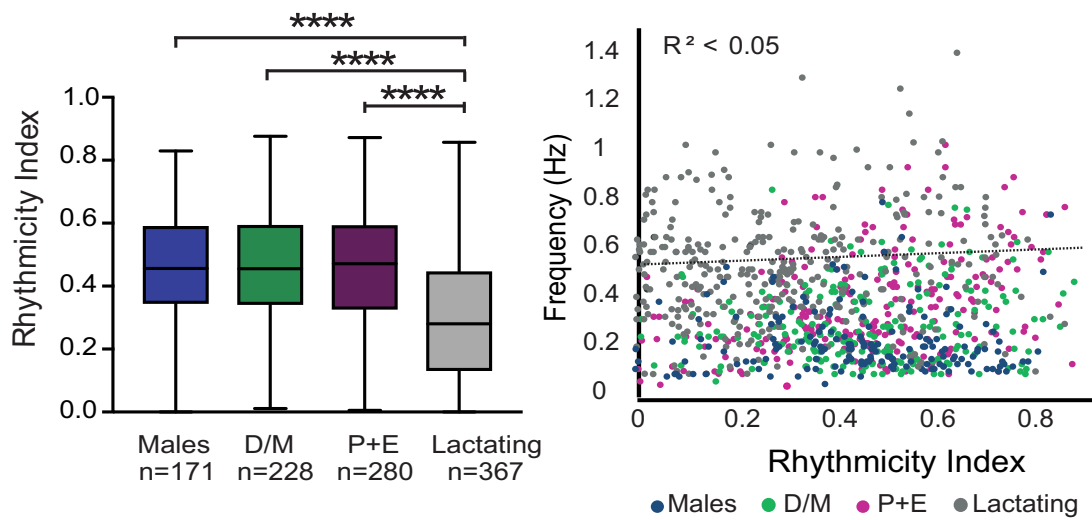

Figure 3. Rhythmicity, but not functional connectivity, of TIDA neurons is affected in lactating dams. $\boldsymbol{A}$, Representative network maps of the functional connectivity in DAT-GCaMP3 neurons in the dmArc of adult male $(\boldsymbol{A} \boldsymbol{a})$, female in diestrus/metestrus $(\mathrm{D} / \mathrm{M} ; \boldsymbol{A} \boldsymbol{b})$, female in estrus (from the proestrus + estrus group; $\mathrm{P}+\mathrm{E} ; \boldsymbol{A c})$, and lactating dam $(\boldsymbol{A d})$. Color coding represents the degree of correlation between neuron pairs. $\boldsymbol{B} \boldsymbol{a}-\boldsymbol{d}$, Representative autocorrelation from one of the neurons from maps shown in $\boldsymbol{A}$ for the respective groups. $\boldsymbol{B} \boldsymbol{a}$, Autocorrelogram illustrates the oscillation period $(T)$, the amplitude of the first trough $(\alpha)$, and the amplitude of the second peak $(\beta)$; the RI was defined as $\mathrm{RI}=\beta / \alpha$. $\mathrm{C}$, Scatter plots represent mean values of the correlation matrix between groups and SEM. There are no significant differences $(p=0.31-0.87)$. One-way ANOVA with Tukey's multiple comparison used as post hoc test. $n$ indicates the number of network maps per hemisphere. D, Box plots represent the interquartile ranges (square) and median (line). Values with whiskers indicate minimum and maximum values of the RI. The RI of the lactating group was significantly lower than the RI of the other groups. ${ }^{* * *} p<0.001$ (Kruskal-Wallis with Dunn's multiple comparison as post hoc test). $n$ indicates the number of cells. All other comparisons between groups are nonsignificant. Scale bar: (in $\boldsymbol{A d}) \boldsymbol{A a}-\boldsymbol{d}, 50 \mu \mathrm{m}$. 3V, Third ventricle. $\boldsymbol{E}$, The correlation between the $\mathrm{Ca}^{2+}$ oscillation frequency and the Rl is low, suggesting that the speed of the oscillation is independent of the rhythmicity.

\section{Reversibility of the TIDA neuron network during weaning}

Giving birth and nursing are, as a rule, recurring events for mouse dams (and women) (Livingston, 2015). At the pituitary level, multiple successful pregnancies have been shown to reinforce lactation-associated plastic changes (Hodson et al., 2012). We therefore sought to establish to what extent the frequency changes associated with lactation in TIDA neurons are persistent and/or accentuate with repeated pregnancies. We compared the frequency of $\mathrm{Ca}^{2+}$ oscillations in nulliparas, during lactation in primipara mice, in 3 weeks weaned primipara dams, and in lactating dams following a second pregnancy. Figure $4 A a-d$ shows representative traces of $\mathrm{Ca}^{2+}$ fluctuations in five TIDA neurons from a single slice in a nulliparous (in estrus), a primipara-lactating (same as in Fig. $2 A c-d$ ), a weaned female in estrus, and a lactating dam following a second pregnancy (L2). As described above, oscillation frequency was significantly higher in the lactating dams (Fig. $2 C ; F_{(2,68)}=19.26, p<0.001$, one-way ANOVA). No significant difference was found between the averages for the first and second lactation ( $p=0.06$, Tukey multiple comparisons, which followed one-way ANOVA). However, there might be subtle differences that do not emerge when the overall mean frequency is compared between slices but are significantly different when compared as individual cells $\left(t_{(358)}=2.95, p=0.003\right.$, unpaired $t$ test). Notably, however, TIDA oscillation frequency 
Aa

Nulliparous

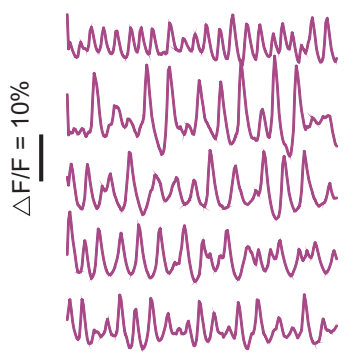

Ab

L1

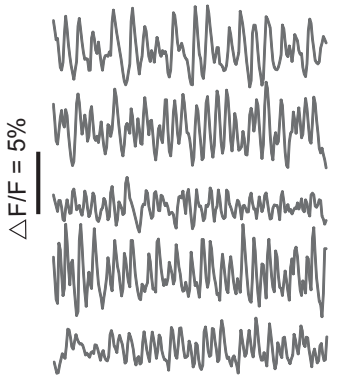

Ac

Weaned

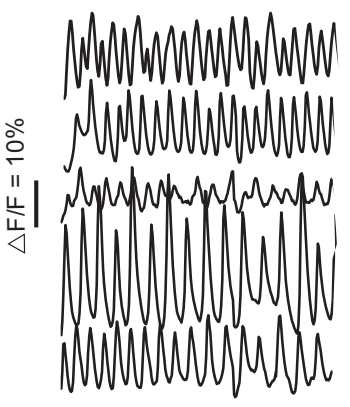

D

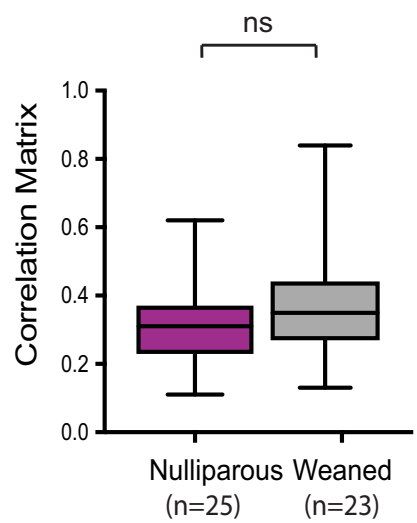

Ad

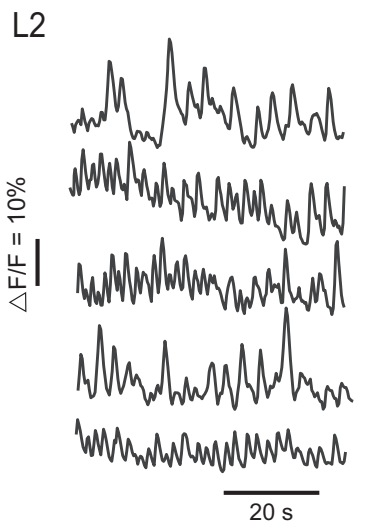

$\mathbf{E}$

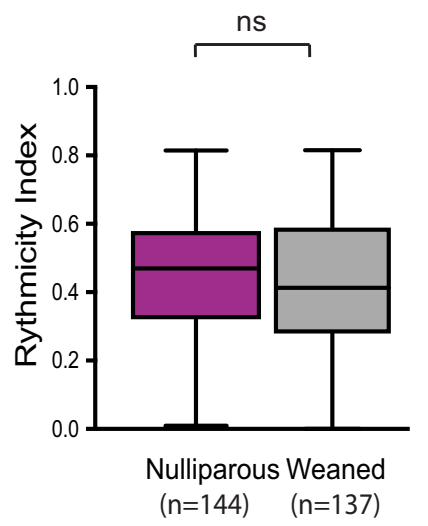

Figure 4. Lactation-associated network changes reverse on weaning of pups. $\boldsymbol{A}$, Representative concomitant traces of Ca ${ }^{2+}$ fluctuations in DAT-GCaMP3 neurons in the dmArc from the same slice in nulliparous female in estrus $(\boldsymbol{A} \boldsymbol{a})$, primipara lactating (L1) dam (Ab), dam in estrus, 3 weeks after weaning (Ac), and lactating dam following a second pregnancy (L2; $\boldsymbol{A d}$ ). B, Box plot represents the interquartile ranges (square) and median (line). Values with whiskers indicate minimum and maximum values of the oscillation frequency. Note significantly lower frequency in weaned dams compared with L1 and L2. ${ }^{* *} p<0.01$ (one-way ANOVA with Tukey' multiple comparison as post hoc test). ${ }^{* * *} p<0.0001$ C, There is no significant difference between the average frequency of the $\mathrm{Ca}^{2+}$ oscillations between the estrus (nulliparous) group and the weaned females during estrus (unpaired Student's $t$ test, $p=0.06$ ). $D$, There is no significant difference between the correlation matrix mean between the estrus (nulliparous) group and the weaned females during estrus (unpaired Student's $t$ test, $p=0.14$ ). $n$ indicates the number of network maps per hemisphere. $\boldsymbol{E}$, There is no significant difference between the rhythmicity index between the estrus (nulliparous) group and the weaned females during estrus (Mann-Whitney, $p=0.33$ ). $n$ indicates the number of cells. $\boldsymbol{A} \boldsymbol{a}, \boldsymbol{A} \boldsymbol{b}$, Same traces as Figures $2 \boldsymbol{A} \boldsymbol{c}, \boldsymbol{d}$, respectively. The number of animals is as follows: $\mathrm{L} 1, n=5 ; \mathrm{L} 2, n=5$; nulliparous, $n=7$; weaned, $n=4$.

in the weaning period was significantly lower than during lactation, and statistically indistinguishable from the estrus period of nulliparous females (Fig. $4 C ; t_{(42)}=0.98, p=0.06$, unpaired $t$ test). We also compared correlation within the network (Fig. $4 D$; $t_{(46)}=1.53, p=0.14$, unpaired $t$ test) and the rhythmicity (Fig. $4 E$; $U=9209, p=0.33$, Mann-Whitney) between the TIDA neurons of nulliparous cycling mice in estrus and of weaned dams in estrus but found no significant difference for either parameter. These data suggest that the lactation-induced resetting of the TIDA network reverses fully once nursing terminates but indicate that there is no "experience" effect of multiple pregnancies at this level of the lactotropic axis.

\section{Changes in intrinsic properties}

Having established that TIDA neurons undergo a reversible acceleration of oscillation frequency during nursing, we next turned our attention to cellular mechanisms that may be involved in this adaptive resetting. This issue was explored by patch-clamp whole-cell recordings from TIDA (DAT-GCaMP3 and DAT-tdT) neurons in lactating and cycling nulliparous females. In current-clamp recordings, the previously described
UP-DOWN state oscillation (Lyons et al., 2010) could clearly be observed in both groups (Fig. 5A,B). Notably, the nadir of the oscillating membrane potential of TIDA neurons from nulliparous females was $-60.3 \pm 1.15 \mathrm{mV}(n=11)$, significantly more hyperpolarized than the TIDA neuron nadir of lactating females $\left(-54.0 \pm 1.87 \mathrm{mV}, n=10\right.$; Fig. $5 C$; $t_{(19)}=2.74, p<0.01$, unpaired $t$ test). To determine whether membrane potential was related to oscillation frequency, depolarization was induced by injecting positive constant current into oscillating cells from nulliparous females. This manipulation resulted in faster oscillations $(n=11$ of 11; Fig. 5A). Contrariwise, hyperpolarization induced by negative current injection to oscillating cells from lactating females resulted in a slower oscillation $(n=8$ of 10 ; Fig. $5 B)$. The relationship between imposed (i.e., by current injection) nadir potential and oscillation frequency in individual TIDA neurons from nulliparous and lactating females is plotted in Figure 5D. These data suggest that the faster TIDA $\mathrm{Ca}^{2+}$ oscillations during lactation may be caused by a depolarizing influence.

Responses of TIDA neurons to a series of square current injections revealed differences between nulliparous and lactating females ( $n=5$ or 6 cells/group; Fig. $5 \mathrm{Ea}$ ): A transient outward rectification was pronounced in nulliparous mice, similar to 
A Nulliparous

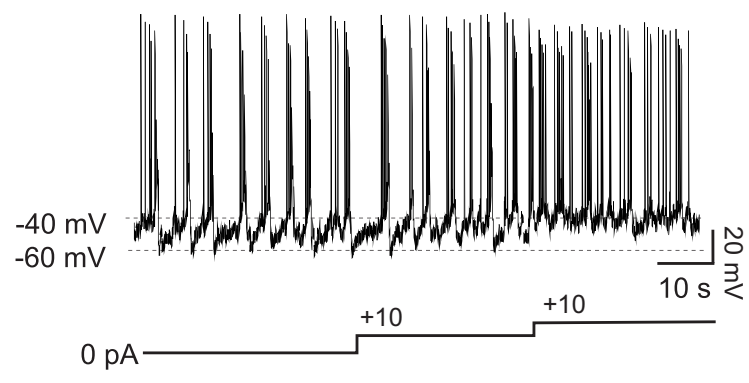

B Lactating

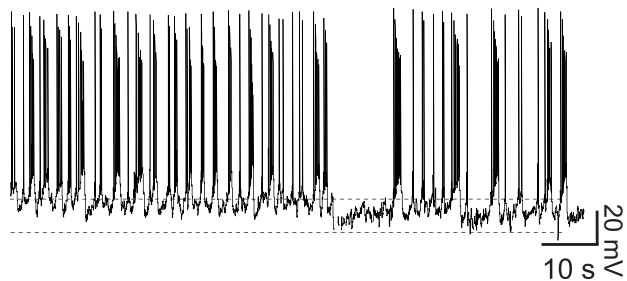

$0 \mathrm{pA}$

$-15$

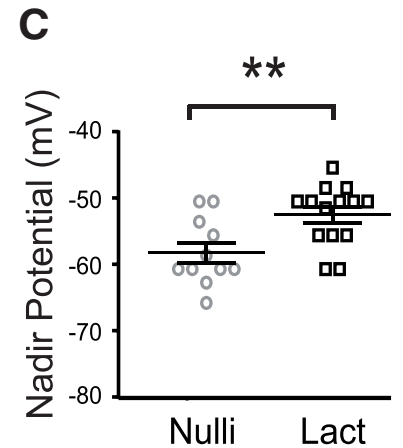

D

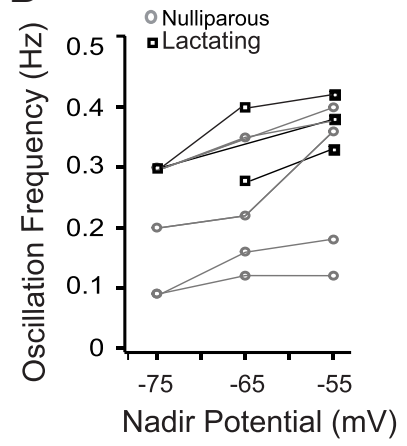

Ea

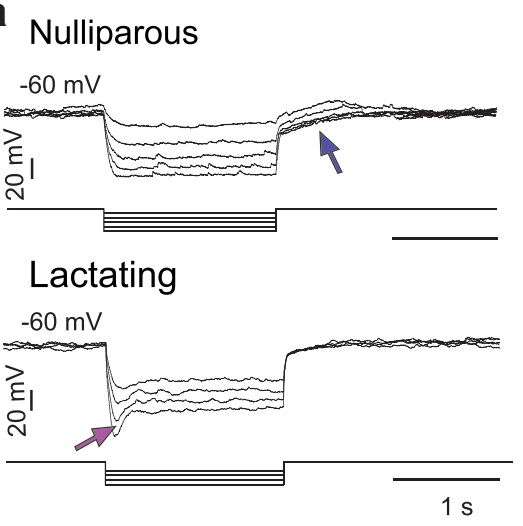

Eb

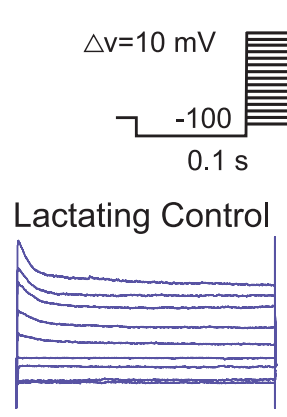

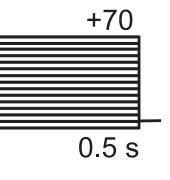

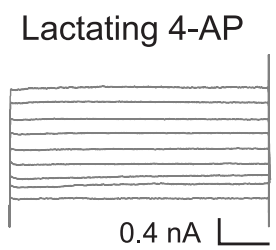

Ec

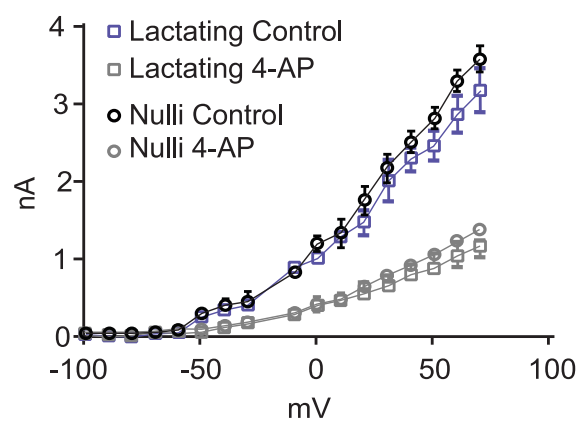

Figure 5. Lactation-associated increase in oscillation frequency is paralleled by depolarization and changes in TIDA membrane properties. A, Whole-cell current-clamp in vitro recording of a DAT-GCaMP3 neuron in the dmArc from a nulliparous female. Membrane potential alternates between hyperpolarized DOWN states and depolarized UP states crowned by action potential discharge. Note increasing frequency of oscillations as depolarizing current of increasing amplitude is injected (10 pA steps). B, Current-clamp recording of a DAT-GCaMP3 neuron from a lactating female. Note faster oscillation frequency that slows down on injection of hyperpolarizing current (-15 pA step). C, The mean DOWN state potential (nadir) of DAT-GCaMP3 dmArc neurons from lactating females is more depolarized $(-54.00 \pm 1.87 \mathrm{mV} ; n=10)$ than in virgin females $(-60.00 \pm 1.15 \mathrm{mV} ; n=11) .{ }^{* *} p<0.01$ (unpaired Student's $t$ test). $\boldsymbol{D}$, Nadir potential plotted against oscillation frequency (data from whole-cell recordings in DAT-GCaMP3 neurons). Note linear relationship in both nulliparous and lactating females, and overall higher oscillation frequencies in lactating dams. Ea, Electrophysiological recordings of DAT-GCaMP3 neuron from a nulliparous (top) and lactating (below) female in the presence of TTX (500 nM), to abolish oscillations and establish a stable baseline, in response to a series of hyperpolarizing square current steps $(-10 /-20$ to $-50 \mathrm{pA})$. Blue arrow indicates outwardly rectifying (A-like) current. Note depolarizing sag in lactating female (absent from nulliparous control), indicative of the $h$-current ( $I_{h}$, magenta arrow). $E \boldsymbol{b}$, Representative traces from a whole-cell voltage-clamp recording from DAT-tdTomato neuron in the dmArc from a lactating dam before and after 4-AP application (4 mm) application. Command voltage protocol to elicit A-like $\mathrm{K}^{+}$current shown above. A-type currents were evoked in response to $10 \mathrm{mV}$ membrane potential steps from -80 to $70 \mathrm{mV}$ after a $-100 \mathrm{mV}$ prepulse. Ec, Current-voltage curves from nulliparous and lactating dams in the presence or absence of 4-AP. No significant difference was found between control and 4-AP conditions $(p=0.08, \boldsymbol{F}$ test; $n=5$ for nulliparous; $n=6$ for lactating).

what has been reported in male rats (Lyons et al., 2010), where it has been attributed to an A-type $\mathrm{K}^{+}$current $\left(\mathrm{I}_{\mathrm{A}}\right)$. To determine whether differences in this property could explain the depolarized state of TIDA neurons during lactation, we used voltageclamp recordings and pharmacology to identify $\mathrm{I}_{\mathrm{A}}$ in TIDA neurons from nulliparous and lactating females. An A-type current could be blocked by application of 4-aminopyridine (4-AP) in both groups (Fig. $5 E b, c$ ). No significant difference was found between TIDA neurons from nulliparous or lactating females
$\left(F_{(3,18)}=13.82, p=0.08, F\right.$ test $)$. Thus, we conclude that alteration of $I_{A}$ is not a major contributor to the change in membrane excitability observed in lactating females.

We next turned our attention to the hyperpolarization-activated nonspecific cation current $\left(\mathrm{I}_{\mathrm{h}}\right)$, since it both has been implicated in network oscillations across a wide span of brain regions (Bal and McCormick, 1996; Avella Gonzalez et al., 2015) and can contribute to setting resting membrane potential (Maccaferri et al., 1993; see He et al., 2014), making it an 
A
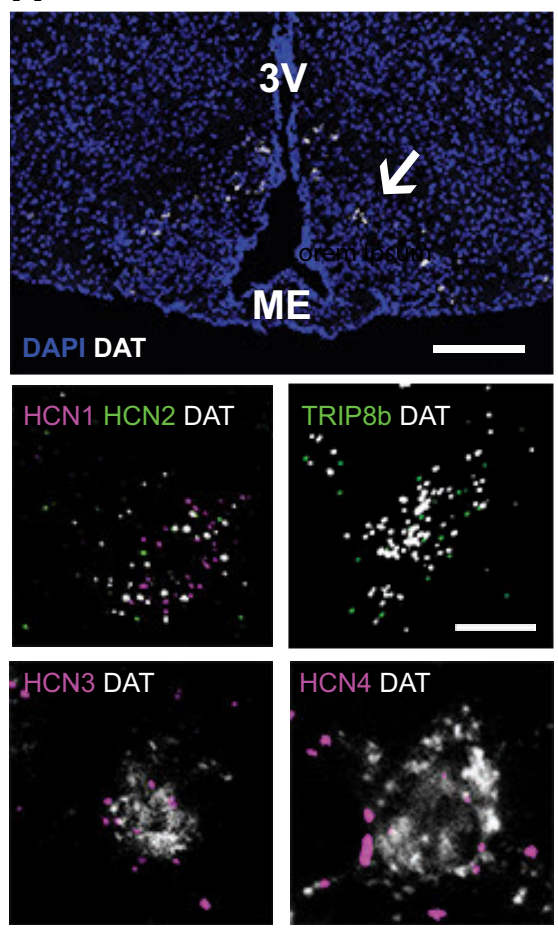

Figure 6. TIDA neurons express HCN channel mRNA. A, Confocal micrograph from the arcuate nucleus of a female nulliparous mouse in estrus after ISH (RNAScope) performed to detect DAT mRNA (white); section counterstained with DAPI (blue) to visualize anatomy. Note distribution of DAT-expressing TIDA cells in the dmArc (arrow). Insets, High-magnification examples of TIDA cells coexpressing DAT (white) and (in clockwise order): the HCN channel 1 (HCN1; magenta) and HCN2 (green); the HCN channel auxiliary subunit, tetratricopeptide repeat-containing Rab8b-interacting protein (TRIP8b; green); HCN3 (magenta); and HCN4 (magenta). $B$, Confocal micrograph organized as in $A$, from the arcuate nucleus of a lactating dam. All RNA transcripts detected in the nulliparous female TIDA neurons can also be found in the same neurons from a lactating female. Scale bars: $A$, $B, 100 \mu \mathrm{m}$; Inset, $20 \mu \mathrm{m}$. 3V, Third ventricle; ME, median eminence. C, Histogram displaying the H-score (see Materials and Methods) of DAT-expressing neurons in the dmArc that coexpress HCN1-4 mRNA. The individual values represent the score from slices from 3 animals in each group. The $\mathrm{H}$-score is not statistically different for either HCN mRNA between the two experimental groups (unpaired Student's $t$ test: $\mathrm{HCN1}, p=0.43$; HCN2, $p=0.45 ; \mathrm{HCN} 3, p=0.13$; HCN4, $p=0.05$ ).

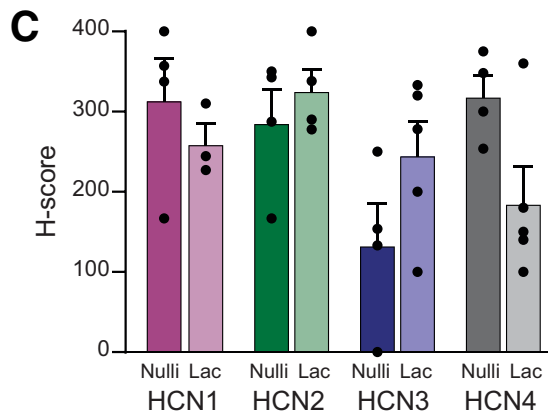

$\mathrm{HCN}$-expressing neurons in this region remains unknown. ISH revealed that mRNA transcripts encoding the $\mathrm{HCN}$ subunits $1-4$ can all be found in TIDA neurons in the arcuate nucleus from nulliparous females during estrus (Fig. $6 A$ ). In all $\mathrm{DAT}^{+}$neurons sampled $(n=22-30$, from 3 mice), at least one subunit was present. Specifically, all (100\%) $\mathrm{DAT}^{+}$neurons expressed HCN1 $(n=22)$ and HCN4 $(n=30) ; 50 \%$ expressed HCN2 $(n=22)$, and $86 \%$ expressed HCN3 $(n=30)$. Furthermore, the HCN channel auxiliary subunit, the tetratricopeptide repeatcontaining Rab8b-interacting protein (TRIP8b) (Santoro et al., 2004; Lewis et al., 2009), was also coexpressed with DAT in the arcuate nucleus (Fig. 6A). Notably, a similar expression pattern was observed in TIDA neurons from three lactating dams (Fig. 6B). All $\mathrm{DAT}^{+}$neurons in lactating females contained mRNA for at least one subunit and $76 \%$ expressed HCN1 $(n=30)$, $92 \%$ expressed HCN2 $(n=31)$, and $100 \% \mathrm{DAT}^{+}$neurons expressed HCN3 $(n=20)$ and HCN4 $(n=22)$. The HCN expression level in $\mathrm{DAT}^{+}$neurons was quantified (H-score, see Materials and Methods); no statistical differences were found between the TIDA populations in nulliparous females in estrus and lactating dams (Fig. 6C; HCN1 $t_{(5)}=0.85, p=0.43 ; \mathrm{HCN} 2 t_{(6)}=0.79$, $p=0.45 ; \quad$ HCN3 $t_{(7)}=1.68, p=0.13$; HCN4 $t_{(7)}=2.36, p=0.059$, unpaired $t$ tests). These data suggest that the depolarization sag in TIDA neurons is likely generated by $\mathrm{I}_{\mathrm{h}}$, but that overt differences in the expression of HCN channels are unlikely to account for the augmentation of this current during lactation.

While $I_{h}$ contributes to rhythmic oscillations in membrane potential in many neurons and other excitable cells (Bal and McCormick, 1996; Avella Gonzalez et al., 2015), earlier studies focusing on male (Lyons et al., 2010) and nonlactating female (Zhang and van den Pol, 2015) rodents have failed to observe attractive candidate to account for the network and cellular changes observed in TIDA neurons during lactation. Previous work in male rats has, however, reported little evidence of the depolarizing sag, indicative of $\mathrm{I}_{\mathrm{h}}$, in TIDA neurons (Lyons et al., 2010). Similarly, we failed to observe a depolarizing sag in any of the recorded TIDA neurons from nulliparous female mice $(n=16$ of 16 ; Fig. $5 E a)$. In notable contrast, a subpopulation ( $n=6$ of 16) of TIDA neurons from lactating females exhibited the depolarizing sag typical of $\mathrm{I}_{\mathrm{h}}$ (Fig. 5Ea,b). Thus, the lactationinduced changes in rhythmic activity appear to be paralleled by alterations of $\mathrm{I}_{\mathrm{h}}$, carried by hyperpolarization-activated cyclic nucleotide-gated (HCN) channels.

Expression of HCN channels has been reported in the hypothalamus (Loose et al., 1990; Kelly et al., 2013), but the exact identity of current sag in oscillating TIDA cells, similar to our present results in nulliparous mice, as noted above. The surprising finding of a depolarizing sag in TIDA cells from lactating females prompted us to evaluate the pharmacological identity of this membrane property by applying the selective $\mathrm{I}_{\mathrm{h}}$ blocker, ZD7288 (Harris and Constanti, 1995). In all six TIDA neurons that displayed a sag on hyperpolarization, the sag was abolished in the presence of ZD7288 (50 $\mu \mathrm{M}$; Fig. 7Aa), concomitant with a membrane hyperpolarization. Quantification of the change in "sag" amplitude $(\Delta \mathrm{mV}$; Fig. $7 A b)$ revealed a significantly greater attenuating effect of ZD7288 in TIDA neurons from lactating dams compared with nulliparous females $\left(t_{(28)}=5.31\right.$, $p<0.001$, unpaired $t$ test). Furthermore, the addition of ZD7288 resulted in a more hyperpolarized nadir potential of 


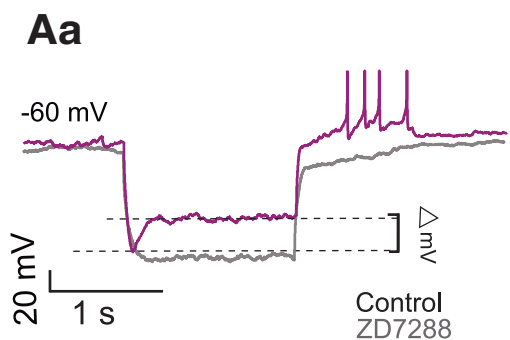

$\mathrm{Ba}$

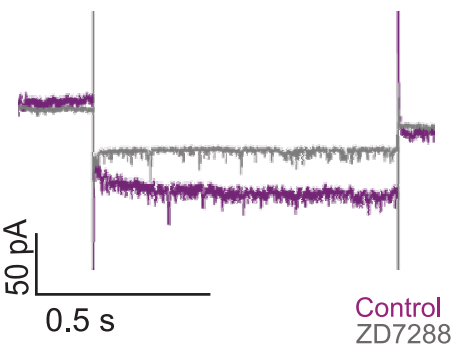

Bd

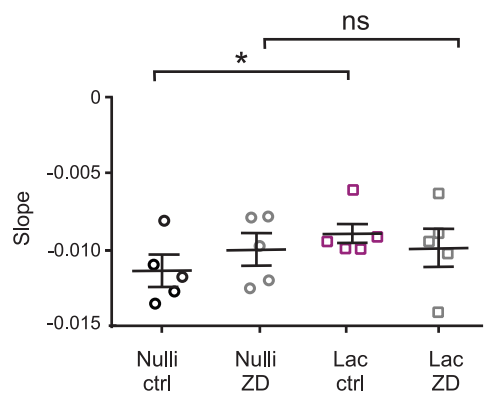

Ab

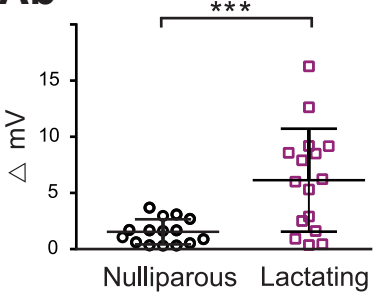

$\mathrm{Bb}$
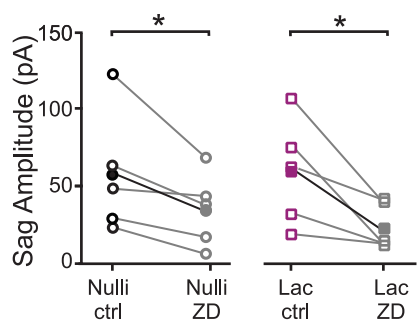

Ac

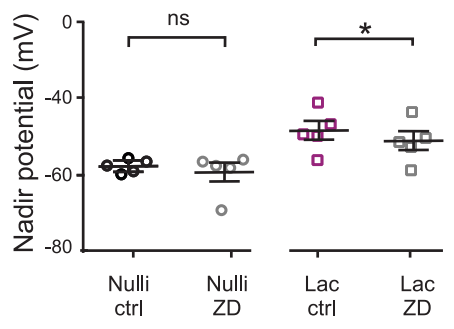

Bc

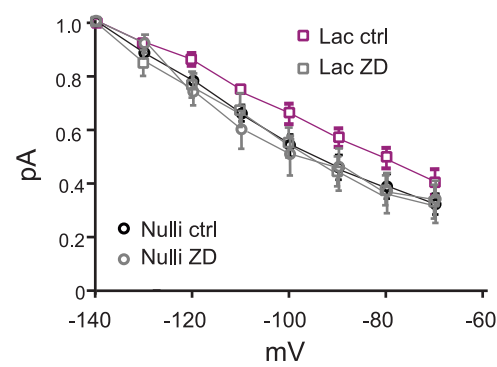

C
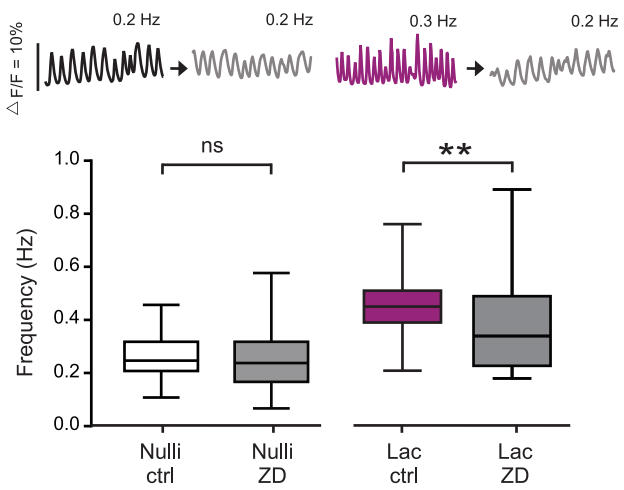

Figure 7. An increase in h-current contributes to increased TIDA oscillation frequency during lactation. Aa, Whole-cell current-clamp in vitro recording of a DAT-GCaMP3 neuron in the dmArc from a lactating dam; negative current step injected to reveal depolarizing sag indicative of h-current (l $h$; magenta trace). Superimposed gray trace represents the same cell recorded in the presence of the $\mathrm{I}_{\mathrm{h}}$-blocker, ZD7288 $(50 \mu \mathrm{m})$. Sag abolished after pharmacological blockade. Ab, The voltage difference between the sag and the steady state of a hyperpolarizing step is significantly larger in TIDA neurons from lactating dams compared with nulliparous females. ${ }^{* * *} p<0.001$ (unpaired Student's $t$ test). Ac, The blockage of $\mathrm{I}_{\mathrm{h}}$ by ZD7288 decreased the nadir potential in lactating dams (Lac) but not in nulliparous females (Nulli). ${ }^{*} p 0.001$ (paired $t$ test). Ba, Representative trace from a whole-cell voltage-clamp recording from DAT-tdTomato neuron in the dmArc from a lactating dam (in the presence of TTX, $500 \mathrm{~nm}$ ) before (magenta) and during (gray) ZD7288 application (50 $\mu \mathrm{m}$ ). Bb, Application of ZD7288 decreased the sag amplitude of $\mathrm{I}_{\mathrm{h}}$ in both nulliparous and lactating dam TIDA neurons. ${ }^{*} p<0.05$ (paired Student's $t$ test). $B C, \mathrm{I}-\mathrm{V}$ curves from nulliparous and lactating dams in the presence or absence of $Z \mathrm{ZD7288}$. $B d$, The comparison of the slope obtained by linear fitting of the I-V curves reveals a difference in lactating dams with respect to nulliparous, which is abolished during Ih blockade by ZD7288. ${ }^{*} p<0.05$ (two-way ANOVA with Sidak's multiple comparison as post hoc test). C, Representative traces of Ca ${ }^{2+}$ fluctuations in a DAT-GCaMP3 neuron before and during ZD7288 application in nulliparous and lactating dam. Box plot represents the effect of bath-applied ZD7288 $(50 \mu \mathrm{m})$ on the frequency of $\mathrm{Ca}^{2+}$ oscillations in DAT-GCaMP3 neurons from nulliparous and lactating females. In nulliparous, the frequency remains unchanged during pharmacological blockade of $\mathrm{I}_{\mathrm{h}}(p=0.77$, paired Student's $t$ test); whereas in lactating females, the frequency decreased during ZD7288 application $(p=0.01 \text {, paired Student's } t \text { test })^{* *} p=0.01$. The frequency was significantly different between control conditions without ZD7288 ( $p=0.03$, unpaired $t$ test).

TIDA cells from lactating dams (Fig. $7 A c ; t_{(4)}=10.04, p<$ 0.001 , paired $t$ test) but did not affect the nadir potential of TIDA neurons from nulliparous mice (Fig. $7 A c ; t_{(4)}=1.068$, $p=0.35$, paired $t$ test). This finding suggests that the depolarized membrane potential of TIDA cells during lactation (Figs. $5 C, 7 A c$ ) might, at least in part, be related to enhanced $\mathrm{I}_{\mathrm{h}}$ in this physiological state.

To further validate the presence of $\mathrm{I}_{\mathrm{h}}$ in TIDA neurons, voltage-clamp recordings were performed in lactating dams for comparison with nulliparous females in estrus (Fig. $7 \mathrm{Ba}$ ) The main effects are presented in Table 1 . Cell capacitance was not significantly different $\left(t_{(8)}=0.15, p=0.88\right.$, unpaired Student's $t$ tests). Membrane potential was analyzed with a $2 \times$ (states: nulliparous vs lactating) $\times 2$ (conditions: control vs ZD7288) ANOVA. The main effects were qualified by a significant interaction between state and condition $\left(F_{(1,8)}=9454, p=0.046\right)$. The difference between states was significant $\left(F_{(1,8)}=8.81, p=0.018\right)$, and the main effect of ZD7288 was also significant $\left(F_{(1,8)}=5.87, p=\right.$ 0.041). Sidak's multiple comparisons test indicated that states and conditions were significantly different $(p<0.05,95 \% \mathrm{CI}$ of the difference $=-10.42$ and -9.74 , respectively). Input resistance was also analyzed with a two-way ANOVA between states and conditions, and it did not show an interaction $\left(F_{(1,8)}=2.07\right.$, $p=0.19)$. Adjusted comparisons indicated that states differ $\left(F_{(1,8)}=5.59, p=0.046\right)$; and in contrast, the conditions did not significantly differ $\left(F_{(1,8)}=1.46, p=0.261\right)$.

The response to hyperpolarizing voltage steps, under TTX application, revealed the presence of a ZD7288-sensitive current in both groups (Fig. $7 \mathrm{Bb}$; nulliparous, $t_{(4)}=2.68, p=0.02$; lactating, $t_{(4)}=7.2, p=0.001$, paired $t$ test). However, the analysis of 
Table 1. Summary of basic electrophysiological properties of TIDA neurons in nulliparous and lactating females ${ }^{a}$

\begin{tabular}{|c|c|c|c|c|}
\hline & Nulliparous & Lactating & State & $p$ \\
\hline $\begin{array}{l}\text { Cell capacitance } \\
\text { Membrane potential (mV) }\end{array}$ & $19.7 \pm 2.7$ & $20.3 \pm 3.0$ & $p=0.88$ & \\
\hline Condition & Control & $-51.4 \pm 0.9$ & $-42.74 \pm 3.3$ & $\begin{array}{l}\text { Main effect of states: } p=0.018^{*} \\
\quad \text { Conditions: } p=0.041^{*}\end{array}$ \\
\hline $\begin{array}{l}\text { ZD } \\
\text { Input resistance (G } \Omega \text { ) }\end{array}$ & $-51.2 \pm 0.5$ & $-44.6 \pm 2.8$ & Interaction: $p=0.046^{*}$ & \\
\hline $\begin{array}{l}\text { Condition } \\
\text { ZD }\end{array}$ & $\begin{array}{l}\text { Control } \\
0.6 \pm 0.2\end{array}$ & $\begin{array}{l}0.7 \pm 0.2 \\
-3.5 \pm 1.4\end{array}$ & $\begin{array}{l}-2.1 \pm 0.5 \\
\text { Conditions: } p=0.262 \\
\quad \text { Interaction: } p=0.19\end{array}$ & Main effects of state: $p=0.046^{*}$ \\
\hline
\end{tabular}

${ }^{a}$ Baseline electrophysiological properties of TIDA neurons in nulliparous and lactating females before and during ZD7288 application. Experiments were performed in the presence of TTX. Data are mean \pm SEM; $n=5$ for each group.*Two-way ANOVA and Sidak's test as a post hoc test $(p<0.05)$.

the currents in response to consecutive command voltage steps indicated a greater sensitivity to ZD7288 in TIDA neurons from lactating mice in comparison with nonlactating mice (Fig. $7 \mathrm{Bc}$ ). Notably, the slope of the I-V curves from TIDA cells during lactation differs significantly from those from nulliparous in control conditions (Fig. $7 B d ; F_{(1,8)}=8.337, p=0.01$, two-way ANOVA), but the application of ZD7288 eliminates that difference $\left(F_{(1,8)}=0.7658, p=0.395\right.$, two-way ANOVA, Sidak's comparison). Thus, while $\mathrm{I}_{\mathrm{h}}$ can be detected through voltage clamp in nulliparous females, this current is enhanced in lactating dams. The induction or upregulation of this current is thus a candidate to explain, at least in part, the depolarized nadir potential and faster oscillations that TIDA neurons exhibit during nursing.

To test this hypothesis, we assessed whether pharmacological blockade of $\mathrm{I}_{\mathrm{h}}$ affects oscillation frequency recorded at the network level. Thus, ZD7288 $(50 \mu \mathrm{M})$ was applied during visualization of $\mathrm{Ca}^{2+}$ oscillations in DAT-GCaMP3 females. In oscillating TIDA cells from nulliparous females $(n=59)$, the frequency was not significantly affected by $\mathrm{I}_{\mathrm{h}}$ blockade (Fig. $7 C ; t_{(58)}=1.06$ $p=0.77$, paired $t$ test). In contrast, in TIDA cells from lactating females $(n=72)$, the mean frequency was significantly reduced in the presence of ZD7288 (Fig. 7C; $t_{(71)}=3.28 p=0.01$, paired $t$ test), supporting a role for augmented $\mathrm{I}_{\mathrm{h}}$ in accelerating network rhythms during nursing. Notably, the frequency was significantly different between nulliparous and lactating females under control conditions $\left(t_{(129)}=0.26, p=0.03\right.$, unpaired $t$ test $)$.

\section{Discussion}

Few, if any, physiological life events rival the scope and impact of adaptive changes that pregnancy and nursing impose on the body. Virtually all organ systems undergo profound structural and functional modifications to prepare the mother for carrying, giving birth to, and nursing her offspring from conception to weaning. In order to organize, coordinate, and properly sequence these events, the CNS also undergoes reorganization in key circuits (see Brunton and Russell, 2008; Elyada and Mizrahi, 2015). In particular, such changes should involve the networks that control the secretion of hormones that define maternal physiology and behavior. Here, using $\mathrm{Ca}^{2+}$ imaging, ISH, and electrophysiological recordings, we show that TIDA neurons, the main regulator of pituitary prolactin release, shift to faster oscillation frequencies during lactation (but not during the course of the estrous cycle), that this is a reversible phenomenon, and present an upregulation of $I_{h}$ as one of the candidate mechanisms for the resetting of rhythms in the nursing dam.

Earlier work has described altered neurochemistry and modulation of TIDA neurons that allow for a sustained hyperprolactinaemia during lactation that, under most other stages in life, is corrected by powerful feedback mechanisms (see Le Tissier et al., 2015). Thus, the increase in dopamine output at the neurovascular interface in the median eminence, which is normally triggered when circulating prolactin rises, is now abolished. Indeed, indices of dopamine release at the median eminence drop during lactation (Selmanoff and Wise, 1981; Ciofi et al., 1993). This has been attributed to suppressed biosynthesis through downregulation of expression (Wang et al., 1993) and phosphorylation (Feher et al., 2010; Romanò et al., 2013) of TH, and a blunted ability of prolactin to trigger key intracellular signaling pathways (Anderson et al., 2006). Diminished dopamine production is further paralleled by an induction of the peptide, enkephalin (Ciofi et al., 1993; Merchenthaler, 1993; Yip et al., 2019), which may inverse the action of TIDA neurons on prolactin release (see Le Tissier et al., 2015). We demonstrate here that neuroendocrine adaptation to motherhood also involves changes in the dynamics of TIDA network activity.

Thus, the transition to motherhood appears to involve not only changes in what is released from TIDA neurons, and the influence of incoming hormonal signals, but also how the neurosecretory signals are released. Interestingly, oscillation frequency was increased only in lactating animals but not in the $\mathrm{P}+\mathrm{E}$ group, although the latter period is also typically characterized by elevated circulating prolactin (Ronnekleiv and Kelly, 1988; Szawka et al., 2007). Thus, it may be speculated that, while dynamic recalibration of TIDA rhythms contributes to sustained hyperprolactinemia during lactation, brief serum peaks of prolactin, such as those within the estrous cycle, result from a qualitatively different modulation of the system. This possibility should, however, be considered with a caveat: if the pre-estrus peak is preceded by a very transient frequency shift that can only be recorded for a brief time, it could have escaped detection in our $\mathrm{Ca}^{2+}$ imaging experiments. At the receiving end of the dopamine signal (i.e., the pituitary lactotrophs), there is a concomitant consolidation of functional connectivity during lactation (Hodson et al., 2012). A full understanding of how the dopamine-prolactin axis adapts for nursing will thus need to consider the cumulative effects of changes in both sender (TIDA) and receiver (pituitary).

MRI has revealed consistent structural modifications in the cerebral cortex of pregnant women (Hoekzema et al., 2017). Overall, published pregnancy- and/or lactation-associated CNS changes generally consist of alterations in structure or gene expression (e.g., Theodosis et al., 1986; Shingo et al., 2003; Meurisse et al., 2005; Cortes-Sol et al., 2013). In comparison, literature describing functional puerperal brain plasticity is scarce, with the exception of work identifying how the maternal brain is reorganized to detect and integrate different pup-generated sensory signals (Marlin et al., 2015). These studies offer a precedent for a dynamic reorganization of the dam's brain, as we report 
here for a hypothalamic population. In a previous study, where TIDA electrical activity was recorded in loose-patch configuration, the oscillation period was not found to be different between male, virgin female, and lactating mice (Romanò et al., 2013). It is possible that the recording technique, which excludes subthreshold activity, and the smaller number of cells included, precluded detection of the changes we report here. The unbiased nature and large cell yield of $\mathrm{Ca}^{2+}$ imaging optimize chances of identifying alterations at the population level.

Our work further identifies augmentation of $\mathrm{I}_{\mathrm{h}}$ as a candidate mechanism to account for the increased TIDA frequency in dams. This current is implicated in network rhythmicity (see Luthi and McCormick, 1998) and contributes to depolarization of the resting membrane potential (Maccaferri et al., 1993; see He et al., 2014), as observed in the lactating mothers (present results). Indeed, we have described a correlation between depolarization and oscillation frequency in mouse TIDA neurons (Stagkourakis et al., 2018), and the present data show that pharmacological blockade of $\mathrm{I}_{\mathrm{h}}$ reduces the lactation-associated fast rhythm, similar to the rate of nulliparous dams.

The voltage sag typical of $\mathrm{I}_{\mathrm{h}}$ is not apparent in TIDA neuron current-clamp recordings in male juvenile rats (Lyons et al., 2010) or mouse (Zhang and van den Pol, 2015). That does not by necessity mean that the current is fully absent from these neurons. Indeed, indirect evidence supports the functional relevance of $\mathrm{I}_{\mathrm{h}}$ within the system as application of ZD7288 to rat TIDA cells interferes with the ability of D2Rs to modulate oscillation frequency (Stagkourakis et al., 2016), and in the same system we have observed a ZD7288-induced slowing of network rhythms. The failure to visualize voltage sag in somatic current-clamp recordings may reflect a location on dendrites (distant of the location of the recording pipette) (Magee, 1998; Stuart and Spruston, 1998; Notomi and Shigemoto, 2004). In voltageclamp recordings, a ZD7288-sensitive $\mathrm{I}_{\mathrm{h}}$ component could be seen in nulliparous mouse TIDA neurons (current study). Importantly, however, this component was substantially bigger, and could only be seen in current-clamp recordings, in TIDA neurons from lactating dams. We thus conclude that $I_{h}$ is augmented during nursing.

In this context, it should be noted that changes in $\mathrm{I}_{\mathrm{h}}$ are unlikely to exclusively account for the network reorganization of TIDA neurons during lactation. Notably, we observed a threefold increase in input resistance in nursing dams, contrary to what an augmentation in $\mathrm{I}_{\mathrm{h}}$ would be expected to yield. Thus, other membrane properties are also expected to be subject to modulation in the TIDA population in the puerperal state. While our current study suggests that $\mathrm{I}_{\mathrm{A}}$ is not among such conductances, the full identification of these physiological targets is an important future goal. Nonspecific cation conductances carried by transient receptor potential cation channels have been shown to be targets for neuromodulation in TIDA neurons (e.g., Lyons et al., 2010; Briffaud et al., 2015; Blum et al., 2019); their potential role in the transition of TIDA neurons to the high-prolactin state of lactation remains to be determined.

The most parsimonious explanation for the appearance of $\mathrm{I}_{\mathrm{h}}$ in TIDA neurons from lactating dams is an increased transcription of $\mathrm{HCN}$ proteins. Indeed, both $\mathrm{I}_{\mathrm{h}}$ and $\mathrm{HCN}$ expression have in other neuronal systems shown to be sensitive to sex steroid status (Piet et al., 2013; Qiao et al., 2013). However, mRNAs for all HCN subunits, as well as the associated HCN protein TRIP8b (Santoro et al., 2004; Lewis et al., 2009), were readily detectable in TIDA neurons in both nulliparous and lactating females. This semiquantitative analysis revealed that the overall HCN expression was not statistically different between virgin and lactating female mice. An alternative scenario thus merits consideration, taking into account the ultrashort dopaminergic autoinhibitory loop recently described in the TIDA system (Stagkourakis et al., 2016). In the prepubertal male, activation of somatodendritic D2Rs slows TIDA oscillations. Pertinent to the present results, D2Rs can attenuate $I_{h}$ in TIDA neurons (Stagkourakis et al., 2016), respectively, likely through adenylate cyclase inhibition and consequently decreased $[\mathrm{cAMP}]_{\text {intracellular, }}$ a known activator of HCN channels (Parkening et al., 1982; Santoro et al., 1998). Thus, the lactating dam, where TIDA dopamine output has been proposed to be decreased (Demarest et al., 1983; Wang et al., 1993; Nagai et al., 1995), would be likely to experience a decreased D2R-mediated inhibition, leading to increased $[\mathrm{cAMP}]_{\text {intracellular, }}$ which, in turn, would unmask a suppressed $\mathrm{I}_{h}$, resulting in depolarization and faster oscillations.

It seems reasonable that at least some of the pregnancy-and lactation-associated brain adaptations need to be reversible to make possible new gravid cycles (up to eight in the female mouse life span) (Nagai et al., 1995). Yet, examples of such adaptations from the literature have, when assessed, in general demonstrated more or less persistent changes (Macbeth et al., 2008; GalindoLeon et al., 2009; Cohen et al., 2011; Hoekzema et al., 2017; see also Kinsley et al., 2012). In contrast, the present results show that, after weaning, TIDA oscillations are reset to their prepregnancy frequencies. We also assessed whether oscillation frequency differs between a dam's first and second lactation periods. No significant difference was found when the means of the frequencies between animals were compared. However, when the $t$ test was performed on values from individual cells (i.e., a larger sample), the second lactation was marked by significantly higher oscillation frequencies. This could imply a capacity for "learning" that would improve performance with repeated nursing periods. In humans, reproductive experience impacts on nursing such that mothers produce more milk (Ingram et al., 2001), although prolactin levels are lower (Musey et al., 1987; Dos Santos et al., 2015), on a second and subsequent lactation periods.

In conclusion, the results presented here reveal a new level of plasticity in the neuroendocrine system, where the sustained elevations of prolactin that drive maternal physiology and behavior in the nursing state are paralleled by a reversible reconfiguration of the hypothalamic circuit that controls its release. Our work identifies a candidate mechanism in the upregulation of $\mathrm{I}_{\mathrm{h}}$ (likely to be accompanied by further changes in membrane properties) and shows how the maternal brain resets to prepare for the arrival of new offspring.

\section{References}

Anderson GM, Beijer P, Bang AS, Fenwick MA, Bunn SJ, Grattan DR (2006) Suppression of prolactin-induced signal transducer and activator of transcription 5b signaling and induction of suppressors of cytokine signaling messenger ribonucleic acid in the hypothalamic arcuate nucleus of the rat during late pregnancy and lactation. Endocrinology 147:4996-5005.

Augustine RA, Seymour AJ, Campbell RE, Grattan DR, Brown CH (2018) Integrative neuro-humoral regulation of oxytocin neuron activity in pregnancy and lactation. J Neuroendocrinol 30:e12569-e12575.

Avella Gonzalez OJ, Mansvelder HD, van Pelt J, van Ooyen A (2015) Hchannels affect frequency, power and amplitude fluctuations of neuronal network oscillations. Front Comput Neurosci 9:141.

Bal T, McCormick DA (1996) What stops synchronized thalamocortical oscillations? Neuron 17:297-308. 
Blum T, Moreno-Perez A, Pyrski M, Bufe B, Arifovic A, Weissgerber P, Freichel M, Zufall F, Leinders-Zufall T (2019) Trpc5 deficiency causes hypoprolactinemia and altered function of oscillatory dopamine neurons in the arcuate nucleus. Proc Natl Acad Sci USA 116:15236-15243.

Bridges RS, DiBiase R, Loundes DD, Doherty PC (1985) Prolactin stimulation of maternal behaviour in female rats. Science 227:782-784.

Briffaud V, Williams P, Courty J, Broberger C (2015) Excitation of tuberoinfundibular dopamine neurons by oxytocin: crosstalk in the control of lactation. J Neurosci 35:4229-4237.

Brown RS, Kokay IC, Phillipps HR, Yip SH, Gustafson P, Wyatt A, Larsen CM, Knowles P, Ladyman SR, LeTissier P, Grattan DR (2016) Conditional deletion of the prolactin receptor reveals functional subpopulations of dopamine neurons in the arcuate nucleus of the hypothalamus. J Neurosci 36:9173-9185.

Brown RS, Aoki M, Ladyman SR, Phillipps HR, Wyatt A, Boehm U, Grattan DR (2017) Prolactin action in the medial preoptic area is necessary for postpartum maternal nursing behavior. Proc Natl Acad Sci USA 114:10779-10784.

Brunton PJ, Russell JA (2008) The expectant brain: adapting for motherhood. Nat Rev Neurosci 9:11-25.

Butcher RL, Collins WE, Fugo NW (1974) Plasma concentration of LH, FSH, prolactin, progesterone and estradiol-17beta throughout the 4-day estrous cycle of the rat. Endocrinology 94:1704-1708.

Ciofi P, Crowley WR, Pillez A, Schmued LL, Tramu G, Mazzuca M (1993) Plasticity in expression of immunoreactivity for neuropeptide $\mathrm{Y}$, enkephalins and neurotensin in the hypothalamic tubero-infundibular dopaminergic system during lactation in mice. J Neuroendocrinol 5:599-602.

Cohen-Becker IR, Selmanoff M, Wise PM (1986) Inhibitory effects of exogenously induced hyperprolactinemia on the endogenous cyclic release of luteinizing hormone and prolactin in the estyrogen-primed ovarioctomized rat. Endocrinology 119:1718-1725.

Cohen L, Rothschild G, Mizrahi A (2011) Multisensory integration of natural odors and sounds in the auditory cortex. Neuron 72:357-369.

Cortes-Sol A, Lara-Garcia M, Alvarado M, Hudson R, Berbel P, Pacheco P (2013) Inner capillary diameter of hypothalamic paraventricular nucleus of female rat increases during lactation. BMC Neurosci 14:7-8.

Demarest KT, McKay DW, Riegle GD, Moore KE (1983) Biochemical indices of tuberoinfundibular dopaminergic neuronal activity during lactation: a lack of response to prolactin. Neuroendocrinology 36:130-137.

Dorshkind K, Horseman ND (2000) The roles of prolactin, growth hormone, insulin-like growth factor-I, and thyroid hormones in lymphocyte development and function: insights from genetic models of hormone and hormone receptor deficiency. Endocr Rev 21:292-312.

Dos Santos CO, Dolzhenko E, Hodges E, Smith AD, Hannon GJ (2015) An epigenetic memory of pregnancy in the mouse mammary gland. Cell Rep 11:1102-1109.

Dudley CA, Jamison TS, Moss RL (1982) Inhibition of lordosis behavior in the female rat by intraventricular infusion of prolactin and by chronic hyperprolactinemia. Endocrinology 110:677-679.

Ekstrand MI, Terzioglu M, Galter D, Zhu S, Hofstetter C, Lindqvist E, Thams S, Bergstrand A, Hansson FS, Trifunovic A, Hoffer B, Cullheim S, Mohammed AH, Olson L, Larsson NG (2007) Progressive parkinsonism in mice with respiratory-chain-deficient dopamine neurons. Proc Natl Acad Sci USA 104:1325-1330.

Elyada YM, Mizrahi A (2015) Becoming a mother-circuit plasticity underlying maternal behavior. Curr Opin Neurobiol 35:49-56.

Feher P, Olah M, Bodnar I, Hechtl D, Bacskay I, Juhasz B, Nagy GM, Vecsernyes M (2010) Dephosphorylation/inactivation of tyrosine hydroxylase at the median eminence of the hypothalamus is required for suckling-induced prolactin and adrenocorticotrop hormone responses. Brain Res Bull 82:141-145.

Foo KS, Hellysaz A, Broberger C (2014) Expression and colocalization patterns of calbindin-D28k, calretinin and parvalbumin in the rat hypothalamic arcuate nucleus. J Chem Neuroanat 61:20-32.

Fox SR, Hoefer MT, Bartke A, Smith MS (1987) Suppresion of pulsatile LH secretion, pituitary GhRH receptor content and pituitary responsiveness to $\mathrm{GnRH}$ by hyperprolactenemia in the male rat. Neuroendocrinology 46:350-359.

Freeman ME, Kanyicska B, Lerant A, Nagy G (2000) Prolactin: structure, function, and regulation of secretion. Physiol Rev 80:1523-1631.
Galindo-Leon EE, Lin FG, Liu RC (2009) Inhibitory plasticity in a lateral band improves cortical detection of natural vocalizations. Neuron 62:705-716.

Grattan DR (2015) 60 YEARS OF NEUROENDOCRINOLOGY: the hypothalamo-prolactin axis. J Endocrinol 226:T101-T122.

Grattan DR, Steyn FJ, Kokay IC, Anderson GM, Bunn SJ (2008) Pregnancyinduced adaptation in the neuroendocrine control of prolactin secretion. J Neuroendocrinol 20:497-507.

Guillou A, Romanò N, Steyn F, Abitbol K, Le Tissier P, Bonnefont X, Chen C, Mollard P, Martin AO (2015) Assessment of lactotroph axis functionality in mice: longitudinal monitoring of PRL secretion by ultrasensitiveELISA. Endocrinology 156:1924-1930.

Harris NC, Constanti A (1995) Mechanism of block by ZD 7288 of the hyperpolarization-activated inward rectifying current in guinea pig substantia nigra neurons in vitro. J Neurophysiol 74:2366-2378.

He C, Chen F, Li B, Hu Z (2014) Neurophysiology of HCN channels: from cellular functions to multiple regulations. Prog Neurobiol 112:1-23.

Hodson DJ, Schaeffer M, Romanò N, Fontanaud P, Lafont C, Birkenstock J, Molino F, Christian H, Lockey J, Carmignac D, Fernandez-Fuente M, Le Tissier P, Mollard P (2012) Existence of long-lasting experience-dependent plasticity in endocrine cell networks. Nat Commun 3:10.

Hoekzema E, Barba-Müller E, Pozzobon C, Picado M, Lucco F, GarcíaGarcía D, Soliva JC, Tobeña A, Desco M, Crone EA, Ballesteros A, Carmona S, Vilarroya O (2017) Pregnancy leads to long-lasting changes in human brain structure. Nat Neurosci 20:287-296.

Ingram J, Woolridge M, Greenwood R (2001) Breastfeeding: it is worth trying with the second baby. Lancet 358:986-987.

Kalyani M, Hasselfeld K, Janik JM, Callahan P, Shi H (2016) Effects of highfat diet on stress response in male and female wildtype and prolactin knockout mice. PLoS One 11:e0166416.

Katz B, Miledi R (1970) Further study of the role of calcium in synaptic transmission. J Physiol 207:789-801.

Kelly MJ, Zhang C, Qiu J, Ronnekleiv OK (2013) Pacemaking kisspeptin neurons. Exp Physiol 98:1535-1543.

Kinsley CH, Franssen RA, Meyer EA (2012) Reproductive experience may positively adjust the trajectory of senescence. Curr Top Behav Neurosci 10:317-345.

Le Tissier PR, Hodson DJ, Martin AO, Romanò N, Mollard P (2015) Plasticity of the prolactin (PRL) axis: mechanisms underlying regulation of output in female mice. Adv Exp Med Biol 846:139-162.

Lerant A, Freeman ME (1998) Ovarian steroids differentially regulate the expression of PRL-R in neuroendocrine dopaminergic neuron populations: a double label confocal microscopic study. Brain Res 802:141-154.

Levine JD, Funes P, Dowse HB, Hall JC (2002) Resetting the circadian clock by social experience in Drosophila melanogaster. Science 298:2010-2012.

Lewis AS, Schwartz E, Chan CS, Noam Y, Shin M, Wadman WJ, Surmeier DJ, Baram TZ, Macdonald RL, Chetkovich DM (2009) Alternatively spliced isoforms of TRIP8b differentially control h channel trafficking and function. J Neurosci 29:6250-6265.

Livingston G (2015) Family size among mothers. Washington, DC: Pew Research Center.

Loose MD, Ronnekleiv OK, Kelly MJ (1990) Membrane properties and response to opioids of identified dopamine neurons in the guinea pig hypothalamus. J Neurosci 10:3627-3634.

Lorang D, Amara SG, Simerly RB (1994) Cell-type-specific expression of catecholamine transporters in the rat brain. J Neurosci 14:4903-4914.

Luthi A, McCormick DA (1998) H-current: properties of a neuronal and network pacemaker. Neuron 21:9-12.

Lyons DJ, Broberger C (2014) TIDAL WAVES: network mechanisms in the neuroendocrine control of prolactin release. Front Neuroendocrinol 35:420-438.

Lyons DJ, Horjales-Araujo E, Broberger C (2010) Synchronized network oscillations in rat tuberoinfundibular dopamine neurons: switch to tonic discharge by thyrotropin-releasing hormone. Neuron 65:217-229.

Lyons DJ, Ammari R, Hellysaz A, Broberger C (2016) Serotonin and antidepressant SSRIs inhibit rat neuroendocrine dopamine neurons: parallel actions in the lactotrophic axis. J Neurosci 36:7392-7406.

Macbeth AH, Gautreaux C, Luine VN (2008) Pregnant rats show enhanced spatial memory, decreased anxiety, and altered levels of monoaminergic neurotransmitters. Brain Res 1241:136-147. 
Maccaferri G, Mangoni M, Lazzari A, DiFrancesco D (1993) Properties of the hyperpolarization-activated current in rat hippocampal CA1 pyramidal cells. J Neurophysiol 69:2129-2136.

Magee JC (1998) Dendritic hyperpolarization-activated currents modify the integrative properties of hippocampal CA1 pyramidal neurons. J Neurosci 18:7613-7624.

Marlin BJ, Mitre M, D'amour JA, Chao MV, Froemke RC (2015) Oxytocin enables maternal behaviour by balancing cortical inhibition. Nature 520:499-504.

McLean AC, Valenzuela N, Fai S, Bennett SA (2012) Performing vaginal lavage, crystal violet staining, and vaginal cytological evaluation for mouse estrous cycle staging identification. J Vis Exp 67:e4389.

Merchenthaler I (1993) Induction of enkephalin in tuberoinfundibular dopaminergic neurons during lactation. Endocrinology 133:2645-2651.

Meurisse M, Gonzalez A, Delsol G, Caba M, Levy F, Poindron P (2005) Estradiol receptor-alpha expression in hypothalamic and limbic regions of ewes is influenced by physiological state and maternal experience. Horm Behav 48:34-43.

Morishige WK, Rothchild I (1974) Temporal aspects of the regulation of corpus luteum function by luteinizing hormone, prolactin and placental luteotrophin during the first half of pregnancy in the rat. Endocrinology 95:260-274.

Musey VC, Collins DC, Brogan DR, Santos VR, Musey PI, Martino-Saltzman D, Preedy JR (1987) Long term effects of a first pregnancy on the hormonal environment: estrogens and androgens. J Clin Endocrinol Metab 64:111-118.

Nagai J, Lin CY, Sabour MP (1995) Lines of mice selected for reproductive longevity. Growth Dev Aging 59:79-91.

Notomi T, Shigemoto R (2004) Immunohistochemical localization of Ih channel subunits, HCN1-4, in the rat brain. J Comp Neurol 471:241-276.

Parkening TA, Collins TJ, Smith ER (1982) Plasma and pituitary concentrations of $\mathrm{LH}, \mathrm{FSH}$, and prolactin in aging $\mathrm{C} 57 \mathrm{BL} / 6$ mice at various times of the estrous cycle. Neurobiol Aging 3:31-35.

Piet R, Boehm U, Herbison AE (2013) Estrous cycle plasticity in the hyperpolarization-activated current Ih is mediated by circulating 17beta-estradiol in preoptic area kisspeptin neurons. J Neurosci 33:10828-10839.

Qiao GF, Qian Z, Sun HL, Xu WX, Yan ZY, Liu Y, Zhou JY, Zhang HC, Wang LJ, Pan XD, Fu Y (2013) Remodeling of hyperpolarization-activated current, Ih, in Ah-type visceral ganglion neurons following ovariectomy in adult rats. PLoS One 8:e71184.

Qundos U, Johannesson H, Fredolini C, O’Hurley G, Branca R, Uhlén M, Wiklund F, Bjartell A, Nilsson P, Schwenk JM (2014) Analysis of plasma from prostate cancer patients links decreased carnosine dipeptidase 1 levels to lymph node metastasis. Translational Proteomics 2:14-24.

Riddle O, Bates RW, Dykshorn SW (1933) The preparation, identification and assay of prolactin: a hormone of the anterior pituitary. Am J Physiol 105:191-216.

Romanò N, Yip SH, Hodson DJ, Guillou A, Parnaudeau S, Kirk S, Tronche F, Bonnefont X, Le Tissier P, Bunn SJ, Grattan DR, Mollard P, Martin AO (2013) Plasticity of hypothalamic dopamine neurons during lactation results in dissociation of electrical activity and release. J Neurosci 33:4424-4433.

Ronnekleiv OK, Kelly MJ (1988) Plasma prolactin and luteinizing hormone profiles during the estrous cycle of the female rat: effects of surgically induced persistent estrus. Neuroendocrinology 47:133-141.
Sairenji TJ, Ikezawa J, Kaneko R, Masuda S, Uchida K, Takanashi Y, Masuda H, Sairenji T, Amano I, Takatsuru Y, Sayama K, Haglund K, Dikic I, Koibuchi N, Shimokawa N (2017) Maternal prolactin during late pregnancy is important in generating nurturing behavior in the offspring. Proc Natl Acad Sci USA 114:13042-13047.

Santoro B, Liu DT, Yao H, Bartsch D, Kandel ER, Siegelbaum SA, Tibbs GR (1998) Identification of a gene encoding a hyperpolarization-activated pacemaker channel of brain. Cell 93:717-729.

Santoro B, Wainger BJ, Siegelbaum SA (2004) Regulation of HCN channel surface expression by a novel C-terminal protein-protein interaction. J Neurosci 24:10750-10762.

Sauve D, Woodside B (1996) The effect of central administration of prolactin on food intake in virgin female ratos is dose-dependent, occurs in the absence of ovarian hormones and the latency to onset varies with feeding regimen. Brain Res 729:75-81.

Selmanoff M, Wise PM (1981) Decreased dopamine turnover in the median eminence in response to suckling in the lactating rat. Brain Res 212:101115.

Shingo T, Gregg C, Enwere E, Fujikawa H, Hassam R, Geary C, Cross JC, Weiss S (2003) Pregnancy-stimulated neurogenesis in the adult female forebrain mediated by prolactin. Science 299:117-120.

Smedler E, Malmersjo S, Uhlen P (2014) Network analysis of time-lapse microscopy recordings. Front Neural Circuits 8:111.

Stagkourakis S, Kim H, Lyons DJ, Broberger C (2016) Dopamine autoreceptor regulation of a hypothalamic dopaminergic network. Cell Rep 15:735-747.

Stagkourakis S, Perez CT, Hellysaz A, Ammari R, Broberger C (2018) Network oscillation rules imposed by species-specific electrical coupling. Elife 7:e33144.

Stricker P, Grüter R (1928) Action du lobe antérieur de l'hypophyse sur la monté laiteuse. Compt Rend Soc Biol 99:1978-1980.

Stuart G, Spruston N (1998) Determinants of voltage attenuation in neocortical pyramidal neuron dendrites. J Neurosci 18:3501-3510.

Szawka RE, Rodovalho GV, Helena CV, Franci CR, Anselmo-Franci JA (2007) Prolactin secretory surge during estrus coincides with increased dopamine activity in the hypothalamus and preoptic area and is not altered by ovariectomy on proestrus. Brain Res Bull 73:127-134.

Theodosis DT, Chapman DB, Montagnese C, Poulain DA, Morris JF (1986) Structural plasticity in the hypothalamic supraoptic nucleus at lactation affects oxytocin-, but not vasopressin-secreting neurones. Neuroscience 17:661-678

Wang HJ, Hoffman GE, Smith MS (1993) Suppressed tyrosine hydroxylase gene expression in the tuberoinfundibular dopaminergic system during lactation. Endocrinology 133:1657-1663.

Yip SH, Romanò N, Gustafson P, Hodson DJ, Williams EJ, Kokay IC, Martin AO, Mollard P, Grattan DR, Bunn SJ (2019) Elevated prolactin during pregnancy drives a phenotypic switch in mouse hypothalamic dopaminergic neurons. Cell Rep 26:1787-1799.e85.

Zhang X, van den Pol AN (2015) Dopamine/tyrosine hydroxylase neurons of the hypothalamic arcuate nucleus release GABA, communicate with dopaminergic and other arcuate neurons, and respond to dynorphin, Metenkephalin, and oxytocin. J Neurosci 35:14966-14982. 